This item was submitted to Loughborough's Research Repository by the author.

Items in Figshare are protected by copyright, with all rights reserved, unless otherwise indicated.

\title{
Performance of hospital spaces in summer: a case study of a 'Nucleus'-type hospital in the UK Midlands
}

PLEASE CITE THE PUBLISHED VERSION

http://dx.doi.org/10.1016/j.enbuild.2013.07.001

PUBLISHER

(C) Elsevier

VERSION

SMUR (Submitted Manuscript Under Review)

LICENCE

CC BY-NC-ND 4.0

\section{REPOSITORY RECORD}

Giridharan, Renganathan, Kevin J. Lomas, C. Alan Short, and A.J. Fair. 2019. "Performance of Hospital Spaces in Summer: A Case Study of a 'nucleus'-type Hospital in the UK Midlands". figshare. https://hdl.handle.net/2134/12855. 
This item was submitted to Loughborough's Institutional Repository (https://dspace.lboro.ac.uk/) by the author and is made available under the following Creative Commons Licence conditions.

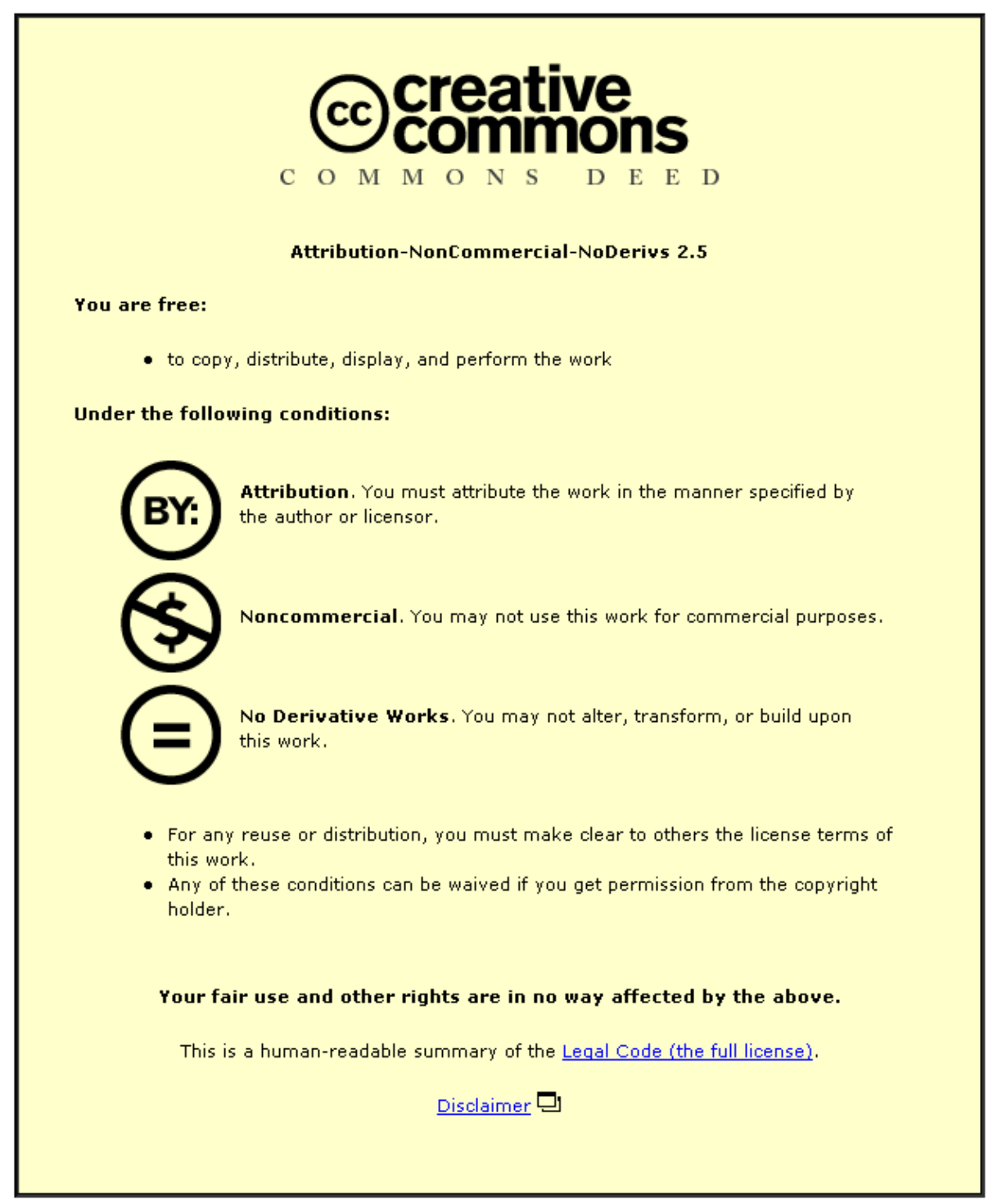

For the full text of this licence, please go to: http://creativecommons.org/licenses/by-nc-nd/2.5/ 


\title{
Performance of hospital spaces in summer: A case study of a 'Nucleus'-type hospital in the UK Midlands.
}

R. Giridharan ${ }^{\mathrm{a} 1}$, K.J. Lomas ${ }^{\mathrm{b}}$, C.A. Short ${ }^{\mathrm{c}}$, A.J. Fair ${ }^{\mathrm{c}}$

${ }^{a}$ Kent School of Architecture, University of Kent, Canterbury, CT2 7NR, UK.

${ }^{\mathrm{b}}$ School of Civil and Building Engineering, Loughborough University, Loughborough, LE11 3TU, UK.

${ }^{c}$ Department of Architecture, University of Cambridge, Cambridge, CB2 1PX, UK.

\begin{abstract}
:
Nucleus-type Hospital in Glenfield comprises connected cruciform blocks with numerous small courtyards between. The hospital has mechanical ventilation and perimeter heating. The wards have a hybrid ventilation strategy with a low rate of mechanical ventilation. Ventilation through windows is the main source of summer time cooling. This paper investigates the summer time performance of spaces that are mechanically ventilated but passively cooled. The paper presents the measured indoor temperatures in selected hospital spaces and compares them with thermal comfort criteria. Finally, future summer conditions for the ward space are predicted using a calibrated multi zone dynamic thermal model.

During June to September 2010, the maximum indoor temperatures in the case study spaces varied between 27.3 ${ }^{\circ} \mathrm{C}$ and $29.3{ }^{\circ} \mathrm{C}$. The nurse station was found to be the hottest area. During this period the performance of most of the monitored spaces was reasonably within the thermal comfort threshold as defined by HTM03-01. The simulation results demonstrate that light-touch low carbon interventions could produce comfortable conditions in bedrooms into the 2050s in UK Midlands.
\end{abstract}

Keywords: summer; hospital; overheating; thermal comfort; natural ventilation; simulation; calibration; low carbon.

\footnotetext{
${ }^{1}$ Corresponding Author. Tel:+441227827969. E-mail: g.renganathan@kent.ac.uk (R.Giridharan, formerly attached to School of Civil Engineering, Loughborough University)
} 


\section{Introduction}

In UK, due to intensity and scale of development, Hospitals on most occasions form deep build environments. These environments can experience overheating during the summer, especially when the outdoor temperature is more than $20^{\circ} \mathrm{C}[1,2,3,4]$. The Design and Delivery of Robust Hospital Environments in a Changing Climate (DeDeRHECC) research project is investigating the impact of summer overheating in hospital campuses operated by four National Health Service (NHS) Acute Trusts. The sites under examination are: Addenbrooke's (Cambridge); Bradford Royal Infirmary; Glenfield Hospital (Leicester); and St Albans City Hospital. In each of these hospitals, 125 spaces within 3 to 4 wards in 2 or more buildings have been monitored since June 2010 .

The degree and duration of overheating, especially in hospital, will depend on geographical location, building design, ventilation strategy and internal gains [3,5,6,7]. Geographically, the Addenbrooke's tower ${ }^{2}$ block is exposed to a climate which is similar to Southern England (warm summer ${ }^{3}$ ) conditions. The building has a hybrid ventilation strategy with a high rate of mechanical ventilation $\left(4 \mathrm{ach}^{-1}\right)$ while radiant ceilings provide space heating [2]. On the other hand, the Nightingale ${ }^{4}$ wards (open wards) in Bradford are exposed to a Northern England (cool summer) climate and they are naturally ventilated with perimeter heating [3]. This paper will focus on Nucleus type hospital, which has a hybrid ventilation strategy with low rate of mechanical ventilation (1.2 to $\left.1.8 \mathrm{ach}^{-1}\right)$ and located in the UK Midlands so that one could have reasonably good understanding on performance of a third commonly occurring hospital building types and its responsiveness to the respective climatic conditions.

The Glenfield ${ }^{5}$ Hospital design, developed in the late 1970s and opened in 1984, was based on the 'Nucleus' concept (Fig. 1). 'Nucleus' is the name given to a way of planning hospitals that was widespread in the UK between the late 1970s and the early 1990s; more than 100 whole 'Nucleus' hospitals or part-schemes were constructed $[9,10]$. 'Nucleus' was a template-based approach which accommodated hospital departments within a standardised cruciform floor area of $1000 \mathrm{~m}^{2}$. These templates were laid out on one or both sides of a connecting corridor (the 'street') to a maximum of two storeys. In theory, any template could be placed above or alongside any other, creating a low-rise regular 'mat plan' [11] with numerous courtyards. One intended feature

\footnotetext{
${ }^{2}$ Built in 1960 s

3 This research considers $1^{\text {st }}$ May to $30^{\text {th }}$ September as summer.

${ }^{4}$ Built in $1900 \mathrm{~s}$

${ }^{5}$ Construction was carried out in two phases. $1^{\text {st }}$ and $2^{\text {nd }}$ phases were completed in 1984 and 1989 respectively.
} 
of the chequerboard layout was that areas could be naturally lit and ventilated from the courtyards where

clinically appropriate [12].

At Glenfield, the principal cooling for the wards is by natural ventilation through window openings. This paper investigates the performance of a naturally cooled Nucleus ward in the UK Midlands, during summer 2010, and simulates light touch low carbon strategies to reduce overheating during future summers. Glenfield Hospital is located in a climate which is transitional between northern and southern England. The historical climate data ${ }^{6}$ for Leicester (UK Midlands), covering the period between 1971 and 2000, shows that the summertime mean maximum and the mean temperatures were in the region of $20.0{ }^{\circ} \mathrm{C}$ and $14.5^{\circ} \mathrm{C}$ respectively [13]. Detailed analysis of 10 years hourly summer data ${ }^{7}$ prior to 2010 shows that only in 2003 were there 9 hours above $30{ }^{\circ} \mathrm{C}$ with a maximum temperature of $31.9^{\circ} \mathrm{C}$ (Fig. 2). Generally, there were fewer than 90 hours over $25.0{ }^{\circ} \mathrm{C}$ in each summer, except for 2003 (97 hours) and 2006 (150 hours). In 2010 there were 36 hours over $25.0^{\circ} \mathrm{C}$ with mean and maximum temperatures in the region of $14.3{ }^{\circ} \mathrm{C}$ and $27.3^{\circ} \mathrm{C}$ respectively. When compared with all the summers of the last decade, it appears that the 2010 summer was mild (Fig.2) and the findings should be viewed taking this into consideration.

\section{Methodology}

The 'DeDeRHECC' research team has developed a standard methodology to study the performance of the hospital environments [1]. A brief description of the methodology is presented here. Firstly, representative recurring 'type' buildings are identified on case study sites and information on their geometry, construction, service strategy and environmental controls is sourced from construction drawings, discussions with facilities managers, and field visits. Secondly, internal temperatures are monitored in selected representative spaces, with the exact choice of spaces for each building being made in consultation with ward staff and facilities managers. Thirdly, the downloaded data are cleaned and results are compared with the thermal comfort criteria described in Health Technical Memorandum 03-01 $1^{8}$ [15], BSEN15251 ${ }^{9}[16]$ and $\operatorname{CIBSE}^{10}$ Guide A [17]. Thresholds for these criteria are presented in Table 1. For a year, the HTM03-01 limiting value is 50 hours. The study assumes that indoor temperatures do not rise above $28^{\circ} \mathrm{C}$ outside the summer period (May to September). Therefore, 50 hours are assumed for the summer period. For any performance evaluation carried out for less than five months

\footnotetext{
${ }^{6}$ Information is extracted from the climate maps produced by the Meteorological office for the Midlands [13].

${ }^{7}$ Cottesmore Meteorological Station, Oakham, Rutland, Leicestershire.

${ }^{8}$ Hours over $28^{\circ} \mathrm{C}$.

${ }^{9}$ Adaptive criteria.

${ }^{10}$ Night time sleeping condition.
} 
of the summer period, the HTM03-01 limiting value is adjusted proportionately for the corresponding period. For the monitoring period ${ }^{11} 1^{\text {st }}$ June to $30^{\text {th }}$ September, the threshold values for HTM03-01, BSEN15251 and CIBSE are 40, 147 and 12 hours respectively. Finally, a sample ward space is modelled using the IES dynamic thermal model [18]. Since the focus of the research project is overheating, the model is calibrated by comparing predicted with measured internal temperatures for the monitored period while keeping HTM03-1 threshold as principal guidance (section 5).

The simulation weather files for the year $2010\left(\right.$ Cottesmore $\left.^{12}\right)$, current ${ }^{13}$ (Cottesmore) and future (Leicester) were created by the 'Prometheus' research team at Exeter University. The future probabilistic weather files were derived using UKCP09 data [20]. A detailed account of this process has been presented elsewhere [1].

\section{Case study description}

At Glenfield Hospital there are 18 wards. The monitoring scope was limited to Wards 18, 19, 27, and 32, and the main waiting area (Fig. 1). This paper focuses on ward 27 because of its relatively high level of overheating (Table 2 and Appendix A) and as a case study to demonstrate the effect of subdividing (section 4) a previously open ward. The construction information and the service strategy are presented in Table 3 and 4 respectively.

At Glenfield fresh air is heated ${ }^{14}$ to $18^{\circ} \mathrm{C}$ and supplied to spaces. The hot water for heating is supplied from the central plant, which has two gas combined heat and power (CHP) units and four gas boilers [23]. The mechanical ventilation rate in Ward 27 is $1.2 \mathrm{ach}^{-1}(135 \mathrm{l} / \mathrm{s})$ [22]. In the bed bay areas, especially in single bed rooms, it is possible to control the perimeter radiator through 'on/off' valves.

\section{Performance of monitored spaces: June to September 2010}

There were 7 'Hobo' loggers in Ward 27 (Fig. 3). The Hobos were cleaned at the time of each installation and prior to the downloading of data by a person assigned by the infection control department using alcohol-based cleaning tissues. The summary of the performance of Ward 27 during the summer of 2010 is presented in Table 2.

\footnotetext{
${ }^{11}$ Total number of hours: 2928. Total number of night time (21:00 to 6:00) hours: 1220.

${ }^{12}$ Cottesmore Meteorological Station, Oakham, Rutland, Leicestershire. The station is located about 20 miles north-east of Leicester. This is the nearest meteorological station that provides all the data that are necessary to create simulation weather files.

${ }^{13}$ Current TRY is based on 1984 to 2004 weather data while the current DSY is 2004. Refer Levermore and Parkinson [19] for the method.

${ }^{14}$ When the outdoor temperature is greater than or equal to $18{ }^{\circ} \mathrm{C}$, the mechanically supplied air is not heated. Between $1^{\text {st }}$ June and $30^{\text {th }}$ September there were 724 hours above $18^{\circ} \mathrm{C}$ out this 583 hours account for daytime (06:00 to 20:00 hrs). BSEN15251 could be applied for this period.
} 
The maximum temperature of $29.3{ }^{\circ} \mathrm{C}$ was observed on $30^{\text {th }}$ June in the space $2 \mathrm{~W} 27-\mathrm{SB} 2$ when the outdoor temperature was $24.3{ }^{\circ} \mathrm{C}$ (Fig. 4). During the study period, the maximum outdoor temperature of $26.9{ }^{\circ} \mathrm{C}$ was recorded on $27^{\text {th }}$ June, however on that day $2 \mathrm{~W} 27-\mathrm{SB} 2$ recorded $28.3{ }^{\circ} \mathrm{C}$ (Fig. 4). There thus appeared to be a lag of three days between the outdoor maximum and the subsequent internal maximum being reached in 2W27SB2. However, 2W27-SB2 demonstrates unusual performance (discussed below), so the above finding should be viewed cautiously. Among the bedrooms, the second-maximum temperature of $28.4{ }^{\circ} \mathrm{C}$ was recorded in $2 \mathrm{~W} 27-\mathrm{MB} 1$ on $29^{\text {th }}$ June when the outdoor temperature was $23.9^{\circ} \mathrm{C}$ (Fig. 5). This space shows a lag of two days. In general, all spaces in ward 27 reached the maximum between $26^{\text {th }}$ and $29^{\text {th }} J_{u n e}{ }^{15}$. The maximum interna ${ }^{16}$ diurnal temperature range of $6.2 \mathrm{~K}$ was recoded in $2 \mathrm{~W} 27-\mathrm{MB} 1$ on $4^{\text {th }}$ July when the outdoor maximum and minimum temperatures were $21.5{ }^{\circ} \mathrm{C}$ and $12.1{ }^{\circ} \mathrm{C}$ respectively (Fig. 5). But, during the study period, the maximum outdoor diurnal temperature range of $14.7 \mathrm{~K}$ was recorded on the $4^{\text {th }}$ June ${ }^{17}$. All the other spaces recorded maximum internal diurnal temperature ranges between $3.7 \mathrm{~K}$ and $5.0 \mathrm{~K}$. However, different spaces recorded the maximum internal diurnal temperature ranges on different days even within the same ward. Generally, the internal maximum diurnal temperature range occurred when the outdoor daily maximum temperatures were above $20.0^{\circ} \mathrm{C}$ (Figs. $4,5 \& 6$ ). The occurrence of maximum internal diurnal temperatures on different climatic condition days and differences in maximum diurnal temperature within the same ward might be directly attributed to outdoor temperature of that day, degree and duration of window opening. This argument is further strengthened by the occurrences of minimum temperatures. The minimum indoor temperature of 18.2 ${ }^{\circ} \mathrm{C}$ was recorded in $2 \mathrm{~W} 27-\mathrm{SB} 2$ on $15^{\text {th }}$ July $(01: 00 \mathrm{hrs})$ when the outdoor temperature was $14.7^{\circ} \mathrm{C}$ (Fig. 4). However, on $17^{\text {th }}$ July (00:00 $\left.\mathrm{hrs}\right)$ when outdoor temperature was identical to that on the $15^{\text {th }}$ July (01:00 hrs), the indoor temperature of $2 \mathrm{~W} 27-\mathrm{SB} 2$ was much higher, $23.2^{\circ} \mathrm{C}$.

All the bedrooms met the HTM03-01 and BSEN15251 Cat II threshold except 2W27-SB2. The single bedroom 2W27-SB2 marginally exceeded the HTM03-01 threshold (Table 2). In contrast, 2W27-SB1, 2W27-SB2 and 2W27-6MB1exceeded the CIBSE threshold. However, only 2W27-SB1 met BSEN15251 Cat I (Fig.7).

All the bed rooms experienced night time overheating. It appears that night time overheating contributed to the exceedance of BSEN15251 Cat I in bedrooms (Fig.7). When the outdoor air temperature exceeded $18^{\circ} \mathrm{C}$, fresh air was supplied without heating (Table 3). During the monitoring period, there were 91 night time hours over

\footnotetext{
${ }^{15}$ Most of the spaces reach their peak temperature within a few hours of the outdoor peak.

${ }^{16}$ Internal maximum and minimum temperature on that day were $26.4{ }^{\circ} \mathrm{C}$ and $20.2^{\circ} \mathrm{C}$ respectively.

${ }^{17}$ Daily maximum and minimum outdoor temperature on that day were $25.3^{\circ} \mathrm{C}$ and $14.7^{\circ} \mathrm{C}$ respectively.
} 
$18{ }^{\circ} \mathrm{C}$ [14]. Further, whenever there were a few hours during the night in excess of $18^{\circ} \mathrm{C}$, the maximum daytime temperatures on that day and during the preceding days were in the region of $23^{\circ} \mathrm{C}$ to $26^{\circ} \mathrm{C}$ (Figs. $4,5 \&$ 6). As a result, the eventual supplied air to the wards could have been further a few ${ }^{\circ} \mathrm{C}$ higher since the supply ducts pick up heat from the fabric. Therefore, for 91 hours, the wards could have been continuously warmed to a higher temperature at night even if the perimeter heaters were turned off. During this period, if the windows were kept closed, the problem could have been aggravated further. The results indicate that windows were kept closed or partially closed for much of the warm nights [23]. The above factors could have resulted in the exceedance of CIBSE threshold.

The nurse station was the hottest area and 2W27-NS exceeded HTM03-01. The nurse station in Ward 27 functioned as a heat sink, because, after use, all the medical equipment, including the machines used for special treatment, light therapy etc are stored here for quick access. At times, in the nurse station, equipment was left connected to power and kept in standby mode to be used when the need arose. As a result, heat from the equipment slowly dissipated into the nurse station. This is not standard practice [23] but was observed on visits to this ward to download data. Further, the nurse station also houses non-medical equipment such as two computers, a photocopier and printer. The heat released from this equipment might also have contributed to the overheating of the nurse station.

The area under study in Ward 27 encompasses a typical arrangement in a part of a cruciform ('Nucleus') template (Figs. $1 \& 3$ ). In the original plan there were no single rooms in this part of Ward 27. There was a fivebed open bay instead of single bedrooms [23]. The nurse station was an open island and there were two multibed rooms with six beds in each. Ward 27 was refurbished in 2009 to create two single bedrooms [23]. As a result the nurse station became an enclosed space with openings towards the corridor. This new arrangement could theoretically have changed the ventilation flow pattern and enhanced the heat trapping tendency (section 7). However, in reality, refurbishment is not the cause for the high temperature in $2 \mathrm{~W} 27-\mathrm{SB} 2$. The single bedroom $2 \mathrm{~W} 27-\mathrm{SB} 1$ is similar to $2 \mathrm{~W} 27-\mathrm{SB} 2$ in terms of service strategy, construction and geometry, but it had very comfortable conditions during summer 2010. It appears that 2W27-SB2 (Fig. 4) encountered additional heat gains compared to $2 \mathrm{~W} 27-\mathrm{SB} 1$ (Fig. 6), especially between $22^{\text {nd }} \mathrm{June}$ and $2^{\text {nd }} \mathrm{July}$. All 70 hours above $28{ }^{\circ} \mathrm{C}$ in 2 W27-SB2 occurred during this period (Figs 4). The outdoor temperature during this period was between 26.9 and $10{ }^{\circ} \mathrm{C}$ with a mean of $18{ }^{\circ} \mathrm{C}$. The outdoor temperature reflects a warm period. Therefore, overheating could have occurred if the room radiator was kept 'on' continuously during the warm period or if there was a 
large amount of medical equipment present. In discussions with the Facility Manager it was suggested that the first reason was the likely cause [23]. Further, if the patient kept the windows closed, heat could also have been trapped. In this respect, the trend of 2W27-SB2 (Fig. 4) was in line with 2W27-SB1 (Fig. 6) after $2^{\text {nd }}$ July. This is an indication that the results could be traced to the preferences of an individual patient. It is beyond the scope of this paper to investigate the reason that this particular patient preferred a high indoor temperature, or whether indeed the patient made a conscious choice of this kind. However this observation argues for adaptive criteria to analyse the hospital performance. But such criteria should accommodate heating and cooling conditions (section 7). Overall, the spaces operated within the limit of reasonable comfort conditions especially with respect to HTM03-01 while maintaining mean temperatures in the range of 23.7 to $25.2{ }^{\circ} \mathrm{C}$.

\section{Modelling and calibration}

To predict the likely temperatures as the climate changes, a multi-zone thermal dynamic model of Ward 27 was constructed and calibrated for $135 \mathrm{l} / \mathrm{s}$ mechanical ventilation rate. In the calibration process priority was given to achieve reasonably close alignment between measured and predicted hours over $28{ }^{\circ} \mathrm{C}$ since it is the NHS benchmark $[1,2]$. The calibration was carried out by focusing on three spaces; 2W27-SB1, 2W27-MB1 and 2W27-NS. The single bedroom 2W27-SB2 was not considered for the calibration exercise since this space had unusual heat gains for a short period (section 4).

Sensitivity analysis was carried out to identify the critical variables necessary to tune the model. The model is sensitive to internal gains in the nurse station, especially heat gains from the equipment, the degree and duration of window openings in all the bedrooms and the degree and duration of door opening ${ }^{18}$ in single bedrooms.

At night, model assumes that in any one hour, $50 \%$ of the doors were opened for five minutes. The window opening regime (Table 4) is one of the most uncertain assumptions but is very critical, especially in making night time predictions. The model cannot accurately reflect an individual's preferences i.e. the window opening regime will not change in line with each and every occupant decision. Nonetheless, in calibration, the predicted data should have a good fit with the measured data over an array of reasonably accurate operating conditions [24]. Therefore, the model used a generalised window opening profile that reasonably reflects the overall trend in the ward (Table 4).

\footnotetext{
${ }^{18}$ The degree and duration of door opening in single bedrooms determines the level of cross ventilation.
} 
Experiments have shown that the largest difference between measured data and predictions occur during periods of high solar radiation intensity (solar gain) and high air flow rate [24]. On most occasions, in bedrooms, during periods of high solar radiation intensity, the predicted temperatures were high compared to those measured (Figs.8 \& 9). A similar trend was observed in nurse station. However, the deviation is marginal in the nurse station due to relatively low solar gain (internal space). The deviations during high solar radiation intensity could be attributed to the weather file used for the simulation i.e. in real situation; solar radiation intensity could have been less than that in the Cottesmore simulation weather file. Furthermore, the model does not take into account the shading of the adjacent wings of the Nucleus building. Overall the deviations of the predicted temperatures during high solar radiation intensity are not significant ${ }^{19}$. The model-predicted temperatures were not very sensitive to prevailing mechanical ventilation rate but were sensitive to high natural ventilation through windows. The model shows that the deviations in the nurse station are due to changes in the internal gains. The model assumes high equipment gains throughout at nurse station but, in the real situation there could have been occasions when the equipment gain was less than or higher than what is assumed.

The predicted maximum temperatures of all the spaces were in reasonable agreement with the measured values (Table 5). In overheating studies, the reliable prediction of peak temperatures is important and any deviation should not exceed $2^{\circ} \mathrm{C}$ [25]. The mean night-time temperature and hours over $28^{\circ} \mathrm{C}$ (HTM03-01 threshold) also show a good agreement with the measured values for all the spaces (Table 5).

\section{Predicted current and future performance}

Predictions were made by assuming that internal gains, occupancy character, window and door opening strategy and services regimes remain unchanged for current as well for future weather periods. In reality, there could be changes, and so the predicted results do not indicate the optimal performance, but they do help to gauge relative performance of different interventions. In addition, hospital services may not be upgraded for long periods of time. The facilities managers have indicated that, since the completion of Glenfield in the 1980s, there have been no major changes to service regimes except in Ward 27 (discussed below); there have only been minor plant upgrades [23].

In late 2011, facilities mangers [23] decided to enhance the mechanical ventilation rate by $0.6 \mathrm{ach}^{-1}(70 \mathrm{l} / \mathrm{s})$ temporarily so that they could protect the ward 27 from construction activities related to new research complex (Fig. 1). In order to gauge the impact of this change, the mechanical ventilation rate of the calibrated model was

\footnotetext{
${ }^{19}$ Maximum deviation is $1.8^{\circ} \mathrm{C}$. Deviation within $2.0^{\circ} \mathrm{C}$ is acceptable [25]
} 
changed to 205 1/s and the results predicted for summer 2010 (Appendix B). A major reduction is shown in the hours over $28^{\circ} \mathrm{C}$ in $2 \mathrm{~W} 27-\mathrm{NS}$. This indicates that a slight increase in mechanical ventilation has the potential to reduce the impact of internal gains. However, the predicted reduction in maximum, minimum and mean night time temperatures were marginal for all the spaces as were the reductions in hours over for CIBSE and BSEN15251 Cat I and II threshold.

The thrust of the DeDeRHECC research project is to test low carbon adaptive/refurbishment measures as a way to improve thermal comfort in hospital buildings $[1,2,3]$. Light touch measures are favoured by NHS Trusts, which are concerned about losing capacity for extended periods of time and of the impact of construction on hospital function [1,3]. Therefore paper investigates the impact of: reducing internal gains at nurse station, horizontal shading above the windows and use of user controlled fans. These interventions are incrementally incorporated in to the calibrated (135 l/s) model in three stages.

Considering the high internal heat gains at the nurse station, the stage-1 intervention looks at the impact of lowering the internal heat gain to the range ${ }^{20} 33 \mathrm{~W} / \mathrm{m}^{2}$ to $44 \mathrm{~W} / \mathrm{m}^{2}$ by reducing the equipment maximum sensible heat gain (total) from $600 \mathrm{~W}$ to $200 \mathrm{~W}$. Stage-2 introduces a horizontal shading device above the windows in addition to the stage- 1 conditions. The projection of the shading device is $1 \mathrm{~m}$ while the thickness is $100 \mathrm{~mm}$. Stage -3 adds to stage-2 a slow-moving fan. The fan becomes operational when the indoor temperature goes beyond $26{ }^{\circ} \mathrm{C}$ [1]. It is assumed that the fan moves to create an air speed of $0.3 \mathrm{~m} / \mathrm{s}$ and decreases the operative temperature by $1.2{ }^{\circ} \mathrm{C}$ [27]. The results presented here were achieved by post processing the stage- 2 data i.e. $1.2{ }^{\circ} \mathrm{C}$ was deducted whenever the temperature exceeded $26^{\circ} \mathrm{C}$ in stage- 2 . The HTM03-01 threshold is not applicable to this option [1]. The predicted results for typical (TRY) and extreme (DSY) summer weather conditions are presented in Table 7. Although the predicted data are processed with respect to CIBSE night time criterion and presented in the Table 7, the results will not be discussed in detail because overheating risks arise during the day, and at night window opening has a substantial effect on internal temperatures, which is difficult to model. However the results could be used to gauge the relative effectiveness of the proposed interventions in the night.

The above-mentioned staged interventions show gradual improvements in terms of the thermal comfort in each space. The improvements during typical years are substantial when compared to extreme years (Table 7). In

\footnotetext{
${ }^{20}$ In a day, the proposed internal gain fluctuates between $33 \mathrm{~W} / \mathrm{m}^{2}$ and $44 \mathrm{~W} / \mathrm{m}^{2}$. The fluctuation is largely due to changes in lighting requirement and occupancy level. For the existing internal gain level refer Table 4.
} 
typical years, all the way to the 2050s, in terms of the HTM03-01 criterion, 2W27-SB1 becomes completely comfortable after stage-2 while 2W27-6MB1 attains marginally uncomfortable, however, 2W27-6MB1 could be made comfortable after the stage- 2 intervention by improving the window controls. In contrast, $2 \mathrm{~W} 27-\mathrm{NS}$ is above the threshold even after the stage- 2 intervention, however, after the stage- 2 intervention, the overheating hours are reduced by $70 \%$ when compared to the existing condition. In terms of BSEN15251 Cat I, 2W27-SB1 and 2W27-6MB1 become completely comfortable after stage-1 and stage-2 respectively. In contrast, in terms of BSEN15251 Cat II without any interventions, 2W27-SB1 and 2W27-6MB1 are comfortable all the way to the 2050s.

In extreme years, all the way to the 2050s, in terms of the HTM03-01 criterion, none of the spaces will be comfortable even after all three stages of interventions. In terms of BSEN15251 Cat I, 2W27-SB1 and 2W276MB1 could achieve complete comfort after the stage-3 intervention; however, it is possible to make 2W27-SB1 completely comfortable after the stage- 2 intervention by improving the window controls since the deviation is very marginal. In terms of BSEN15251 Cat II, 2W27-SB1 and 2W27-6MB1 become comfortable after stage-1 and stage-2 interventions respectively; however, it is possible to make 2W27-SB1 and 2W27-6MB1 comfortable with the existing condition and stage-1 interventions respectively by improving the window controls.

\section{Discussion}

During the monitored period, the maximum indoor temperatures of the spaces under investigation varied between $27.7^{\circ} \mathrm{C}$ and $29.3{ }^{\circ} \mathrm{C}$ while the minimum indoor temperatures varied between $18.2{ }^{\circ} \mathrm{C}$ and $22.5^{\circ} \mathrm{C}$. The maximum indoor diurnal temperature ranges between $3.7 \mathrm{~K}$ and $6.2 \mathrm{~K}$ and these ranges did not occur on the same day even within the same ward. The analysis of the monitored data and the modelling work showed that the degree and duration of window opening has a major impact on the occurrence of maximum diurnal temperature range on different days within the same ward. This has implications both in terms of comfort and energy consumptions [1,2]. It is good to have a large indoor diurnal temperature range on hot days since it helps to slow down the overheating process [3]. The data shows that a maximum diurnal temperature range of $4 \mathrm{~K}$ or more with a minimum internal temperature of $20{ }^{\circ} \mathrm{C}$ could lead to comfortable conditions. In contrast, low indoor diurnal temperature range during hot days will accelerate overheating process. The dynamic thermal models were able to capture this trend. Furthermore, during calibration the model showed that overheating in one room could impact on adjacent rooms, especially when a space has a very low level of mechanical 
ventilation rate similar to that prevailing in Glenfield Hospital. It is important for the ward staff to be aware of this issue and manage the window-opening, the heat-radiating equipment and perimeter heater controls during hot days. This issue is highlighted in UK Carbon trust report on Hospitals [4].

During study period, single and multibed rooms met the HTM03-01 and BSEN15251 Cat II thresholds except 2W27-SB2. However, during this period both single and multibed rooms did not meet the CIBSE night time criterion. At the same time, these spaces did not meet BSEN15251 Cat I criterion except 2W27-SB1. However, if the monitored results are considered within an annual perspective while assuming that the overheating does not occur outside May to September period, the all bedrooms could meet BSEN15251 Cat I criterion ${ }^{21}$. The UK Midland climate during 2010 summer was relatively mild (Fig.2) and spaces were able to meet reasonable comfort conditions, except in the night. However, it is very clear that in hot summers like 2003 and 2006 (Fig.2) the spaces will not be comfortable without additional means of cooling. On the other hand, in hospitals, eliminating heating periods from data sets and applying BSEN15251 is very difficult due complex service strategies. Study was able to apply BSEN15251 by considering the data set from overall service strategy (Table 1). The application of adaptive criteria, especially considering the future hot summers, is more suitable for less sensitive (in terms of infection) wards and the general areas, and they account for large part $(60 \%)$ of the hospital spaces [1]. Therefore, there is need to develop hospital specific adaptive criteria. It should be noted BSEN15251 Cat I limits which are suitable for wards, overlap with CIBSE adaptive band for office buildings with heating and cooling for reasonable range of running mean [16,17]. Therefore, one could argue that, in principle, CIBSE adaptive band for office buildings with heating and cooling has the potential for application in hospital environment. But this needs to be validated and it could be done by pooling large number of hospital performance data. The case studies carried out by DeDeRHECC could form a platform for such an exercise.

Wards 27 showed a nighttime overheating trend. This will have a significant negative impact on the patient sleeping ability [1]. The model calibration showed this could be avoided to a great extent if the single bedroom doors are kept open while windows in both single and multi-occupancy bedrooms are opened to enhance the cross ventilation across the ward i.e. multibedroom doors are opened all the time and if the single bedroom doors are kept open, these wards could move towards an open ward character ${ }^{22}$. Further, the model shows that if the nurse station (NS) is made an open island, there will be only 14 hours above $28^{\circ} \mathrm{C}$ as opposed to 53 hours

\footnotetext{
${ }^{21}$ Spaces were monitored for four months out of five summer months. The missing month is May and occurrence of overheating in May is relatively few compared to other summer months.

${ }^{22}$ Currently total window area is approximately $15 \%$ of bedrooms floor area (Table 4 ).
} 
during summer 2010 (Table 6). However, the NHS is currently converting open wards into multiple single bedroom wards in order to address patient privacy and infection control. Converting open ward into multi single bed ward could results in over heating if the new partitions are not adjusted at the bottom and top to allow cross ventilation. The model shows that partition work carried out in 2009 did not take this into consideration (section 4). However results presented here should be viewed cautiously since the model has its own limitations. The model cannot accurately reflect an individual's preferences. In the model, all the windows follow the same opening profile. This could be corrected by creating window opening profiles that reflect the changes in relation to time, space or quasi-random decisions. However, such an exercise requires considerable time and resources, and most importantly information from clinical staff on occupancy. Furthermore, the model cannot capture the periodic intervention of the facility managers to decrease or increase the heating provision (set point adjustment etc) at the request of the ward staff. There were also periods when the single rooms were unoccupied and multibed rooms were under-occupied. These changes will also influence the control of radiators and windowopening, but this model cannot capture the impact of such changes. There is further uncertainty in the assumptions relating to background infiltration ${ }^{23}$ and the air change rate between room and ceiling ${ }^{24}$. These deviations are unavoidable considering the complexity of the hospital environment, the scope and nature of the service strategies, and regular changes in the patient's (occupant's) character. However, the focus of the paper is to investigate the relative differences in the performance due to the interventions and the model is capable of capturing this change.

The predictions were made assuming that ventilation rates are the same as at the commissioning ${ }^{25}$ stage for current and future. However, the plant and the system are 20 years old and there could be some loss in the ventilation rate due to leakages in the ducting system and reduction in fan efficiency. In order to picture this uncertainty the space was modelled with $0.8 \mathrm{ach}^{-1}(85 \mathrm{l} / \mathrm{s})$ as part of the calibration work. The results of this exercise show that the maximum temperatures ${ }^{26}$ of the spaces for summer 2010 were similar to that of the 135 1/s model (Table 5) for the same period. Furthermore, except for the nurse station, all the spaces met the

\footnotetext{
${ }^{23}$ The model assumes background infiltration as $0.35 \mathrm{ach}^{-1}$.

${ }^{24}$ The air change rate between the rooms and void above the ceiling is assumed to be $0.75 \mathrm{ach}^{-1}$.

${ }^{25}$ In 1989 the ventilation rate was 135 1/s for the area under study.

${ }^{26}$ The maximum temperature of 2W27-SB1, 2W27-SB2, 2W27-6MB1, 2W27-6MB2, 2W27-NS and 2W27-CD were $28.5^{\circ} \mathrm{C}, 28.5^{\circ} \mathrm{C}, 29.5{ }^{\circ} \mathrm{C}, 29.2{ }^{\circ} \mathrm{C}, 29.8^{\circ} \mathrm{C}$ and $28.5^{\circ} \mathrm{C}$ respectively.
} 
HTM03-01 threshold ${ }^{27}$. Therefore, results presented in the Table 7 should be viewed taking the above issue into consideration.

It is important to note that the mechanical ventilation is well below the current HTM03 guidance of $6 \mathrm{ach}^{-1}$, though there is some supplementary flow of air through windows (though these are restricted to $100 \mathrm{~mm}$ opening for perceived patient safety). Predictions showed that the combined (natural and mechanical) maximum ventilation rates in 2W27-SB1, 2W27-SB2, 2W27-MB1 and 2W27-MB2 were $31.2 \mathrm{ach}^{-1}, 31.2 \mathrm{ach}^{-1}, 8.2 \mathrm{ach}^{-1}$ and $16.2 \mathrm{ach}^{-1}$ respectively. Further, the combined mean ventilation flow rates in these spaces were $3.5 \mathrm{ach}^{-1}, 3.5$ $\mathrm{ach}^{-1}, 2.4 \mathrm{ach}^{-1}$ and $4.7 \mathrm{ach}^{-1}$ respectively. However, by maintaining minim $1.2 \mathrm{ach}^{-1}$ at any time, the space was able to achieve reasonable overall comfort condition (section 6). The HTM03-01 does not indicate a flow rate for hybrid ventilation. However it states $6 \mathrm{ach}^{-1}$ is mandatory in wards for natural as well as for mechanical ventilation strategies. The results of this study indicate that the HTM03-01-prescribed 6 ach $^{-1}$ mechanical ventilation rate may not be necessary to create comfortable conditions in Leicester. Our previous research work on Bradford also demonstrated a similar finding [3]. Generally in the Midlands, northern England and Scotland, hospitals could achieve comfortable conditions by combining natural ventilation with a low rate (say $1.5 \mathrm{ach}^{-1}$ ) of mechanical ventilation. In this scenario, the mechanical ventilation will primarily improve the quality of the indoor air rather than creating comfort. Such a strategy could contribute to huge reductions in $\mathrm{CO}_{2}$ emissions. Since 2008 Glenfield Hospital has won carbon reduction award presented by Carbon Trust of UK [23]. A strategy to operate the hospital under low rate of mechanical ventilation could be a prime contributor to achieve this award in addition to use of CHP.

Some parts of the internal courtyards are being converted into additional ward/clinical spaces (Fig. 1). This development, common in many UK Nucleus-type hospitals and driven by a wish to maintain adjacencies between medical functions, is resulting in deep plan buildings and diminishing the prospects of cross ventilation and daylight. However detail investigation on this issue is beyond the scope of this paper.

The light touch measures proposed for Glenfield could be achieved without compromising bed space, patient comfort and safety. Similar light touch measures were proposed for Nightingale wards in Bradford [3]. The predictions for Ward 27 show that light-touch low carbon interventions could have a positive impact on indoor comfort conditions in hospital wards in UK Midlands, where the impact of climate change is not severe. The

\footnotetext{
${ }^{27}$ The hours over 28.0 in 2W27-SB1, 2W27-SB2, 2W27-6MB1, 2W27-6MB2, 2W27-NS and 2W27-CD were $10,8,35,18,103$ and 13 respectively.
} 
predictions also indicate that internal and solar gains play a major role in overheating the ward spaces with a low rate of mechanical ventilation. To a large extent the overheating due to internal gain could be avoided through proper management/storage of heat radiating equipment. The horizontal shading ( $1 \mathrm{~m}$ projection) over the west facing windows could reduce the maximum and total summer time solar gain by $25 \%$ and $30 \%$ respectively at Glenfield ${ }^{28}$ Hospital, even during extreme years. Similarly, introduction of 'butter fly' shading device on southern façade of Addenbrooke's tower ${ }^{29}$ reduced the maximum and total summer time solar gain by $75 \%$ and $65 \%$ respectively, even during extreme years [2]. Further reduction in overheating could be made if the restrictions on window opening were relaxed, perhaps with the provision of an appropriate 'guard' for patient safety [2], or if louvred panels, separate from the windows, were used for ventilation. This was demonstrated in the Bradford study [3]. On the other hand, for the current and future Midland climate, the impact of a slowrotating fan on reducing the overheating hours in hospital wards is substantial. Furthermore, fans are a low energy and low cost approach to reducing overheating hours in hospitals [1]. In UK, some hospitals have adapted fans for summer time cooling. However there is need for further research on dust and infection control in fan operated environment.

\section{Conclusion}

The paper has summarised the performance of ward 27 at Glenfield Hospital during June to September 2010. As per the monitored results, the major deviation from the comfort criteria was observed in the incidence of nighttime overheating. Partitioning the open wards hampers the summer time cooling in Nucleus type hospitals. Study demonstrates the need for hospital specific adaptive criteria which could accommodate heating and cooling conditions.

For the calibration period, the predicted results of the model show reasonable agreement with measured maximum and mean temperatures, and the HTM03-01 threshold. The study also demonstrates the complexity in calibrating a multi-zone hospital model, especially when there are regular variations in occupancy level, internal gains window opening etc. The results indicate that reasonable comfort conditions could be achieved with a mechanical ventilation rate as low as $1.5 \mathrm{ach}^{-1}$ when there is adequate provisions for window opening.

\footnotetext{
${ }^{28}$ For the existing condition, maximum and the total solar gain during summer 2010 were 2 and $1000 \mathrm{~kW}$ respectively.

${ }^{29}$ For the existing condition, maximum and the total solar gain during summer 2010 were 3.8 and $2029 \mathrm{~kW}$ respectively.
} 
Three sequential interventions show that in UK Midlands the overheating could be controlled into the 2050s for both typical and extreme years through light touch low carbon interventions in Nucleus type hospitals. Proposed interventions could be carried out without compromising on bed spaces and patient's safety. Beyond 2050 these light touch measures may not work and more fundamental interventions may be required. Further research should focus on the impact of encroachment of courtyards in the Nucleus type hospitals.

\section{Acknowledgements}

This work was undertaken at part of the UK Engineering and Physical Sciences Research Council project, 'Design and Delivery of Robust Hospital Environments in a Changing Climate' (EP/G061327/1), which was funded through the Adaptation and Resilience to a Changing Climate programme.

The project team is grateful for the support of the Department of Health and four hospital trusts: Cambridge University Hospitals NHS Foundation Trust, Bradford Teaching Hospitals NHS Foundation Trust, West Hertfordshire NHS Trust, and University Hospitals of Leicester NHS Trust.

The research reported here was undertaken whilst Dr.R.Giridharan at Loughborough University. The work would not have been possible without the assistance of Glenfield Hospital's management, which provided access for data collection and other information about the ward services strategy. The authors would like to extend a special thanks to Mr Martin Owen and Mr Jon Abbot, Facilities Management Office, Glenfield Hospital, for their valuable assistance to this research project. The authors are also grateful to the British Atmospheric Data Centre (BADC) for providing access to weather data, the researchers at Exeter University and the Prometheus project team for provision of current and future weather files, and Mr Louis Fifield for assistance during the monitoring work.

\section{References}

[1] K.J. Lomas, R. Giridharan, Thermal comfort standards, measured internal temperatures and thermal resilience to climate change of free running buildings: a case-study of hospital ward, Building and Environment 55 (2012) 73-95. 
[2] C.A. Short, K.J. Lomas, R. Giridharan, A.J. Fair, Building resilience to overheating into UK hospitals within the constraint of the national carbon reduction target: adaptive strategies for 1960s buildings, Building and Environment 55 (2012) 73-95.

[3] K.J. Lomas, R. Giridharan, C.A. Short, A.J. Fair, Resilience of 'Nightingale' hospital wards in a changing climate, Building Services Engineering Research and Technology 33 (2012) 81-103.

[4] Hospitals: healthy budgets through energy efficiency, Carbon Trust UK , 2010, see at www.carbontrust.co.uk

[5] W. Czarniecki, M. Kopacz, W. Okolowicz, J. Gajewski, E. Grzedzinski, Investigation of the microclimate in hospital wards. Energy and Buildings 15-16(1990/91) 727-733.

[6] J. Skoog, N. Fransson, L. Jagemar, Thermal environment in Swedish hospitals summer and winter measurments. Energy and Buildings 37 (2005) 872-877.

[7] R.L. Hwang, T, P. Lin, M. J. Cheng, J. H. Chien, Patient thermal comfort requirement for hospital environments in Taiwan. Building and Environment 42 (2007) 2980-2987.

[8] Google Earth Image of Glenfield Hospital, Google Earth, Inforterra Ltd and Bluesky, USA, 2012, see at http://www.google.com/earth/index.html (Accessed 20-03-2012).

[9] W.P. James, W. Tatton-Brown, Hospitals: Design and Development, Architectural Press, London, 1986.

[10] D. Stow, 'Transformation in hospital architecture: from the hospital to a healthcare organism', in: S. Prasad (Eds.), Changing hospital architecture, RIBA, London, 2008, pp. 13-49.

[11] E. Mumford, 'The Emergence of Mat or Field Buildings', in: Hashim Sarkis (Eds.), Le Corbusier's Venice Hospital and the Mat Building Revival, Prestel, Munich, 2001, pp. 48-65. 
[12] C. Rawlinson, Nucleus: a comparative evaluation, DHSS, London, 1987.

[13] Regionally Mapped Climate Averages for Midlands, Meteorological Office, UK, 2011, see at http://www.metoffice.gov.uk/climate/uk/averages/regmapavge.html\#midlands (Accessed 05.12.2011).

[14] BADC, British Atmospheric Data Centre, National Centre for Atmospheric Science, National Environmental Research Council, UK, 2012, see at http://badc.nerc.ac.uk/home/index.html (Accessed 16.01.12).

[15] HTM03-01, Health Technical Memorundum: Specialised ventilation for healthcare premises, Part ADesign and installation, Department of Health, UK, 2007, p. 134.

[16] BSEN15251, Indoor environment input parameters for design and assessment of energy performance of buildings addressing indoor air quality, thermal environment, lighting and acoustics, British Standards Institute, Brussels, 2008, p. 56.

[17] CIBSE Guide A:Environmental Design. Chartered Institute of Building Service Engineers, 2006, ISBN 978190387668.

[18] IES, Integrated Environmental Solutions, IES VE Software version 6.4.0.8, 2011, see at http://www.iesve.com.

[19] G.J. Levermore, J.B Parkinson, Analyses and algorithms for new test reference years and design summer years for the UK. Building Services Engineering Research and Technology 27 (2006) 311-325.

[20] M. Eames, T. Kershaw, D. Coley, (2011). On creation of future probabilistic design weather years from UKCP09. Building Services Engineering Research and Technology 32 (2) (2011) 127-142.

[21] HTM55, Health Technical Memorundum 55: Windows, Department of Health, UK, 1998, p.34. 
[22] Commissioning Manual. Commissioning manual of air conditioning and ventilation systems, Glenfield Hospital, Leicester NHS, UK, 1989.

[23] M. Owens, Energy Manager, Leicester NHS Trust, Glenfield Hospital, UK, 2012. The research team had frequent conversations with Mr. M. Owens during the monitoring period and discussed the general maintenance, service strategy and overall performance of the hospital.

[24] P.A. Strachan, Simulation support for performance assessment of building components, Building and Environment 43 (2008) 228-236.

[25] K.J. Lomas, H. Eppel, C.J. Martin, D.P. Bloomfield, Empirical validation of building energy simulation programs. Energy and Buildings 26 (1997) 253-275.

[26] ANSI/ASHRAE 55, Thermal environment condition for human occupancy, American Natational Standards Institute (ANSI), American Society of Heating, Refrigerating and Air conditioning Engineers (ASHRAE) Standard, 2010, p.56. 


\section{Figures}

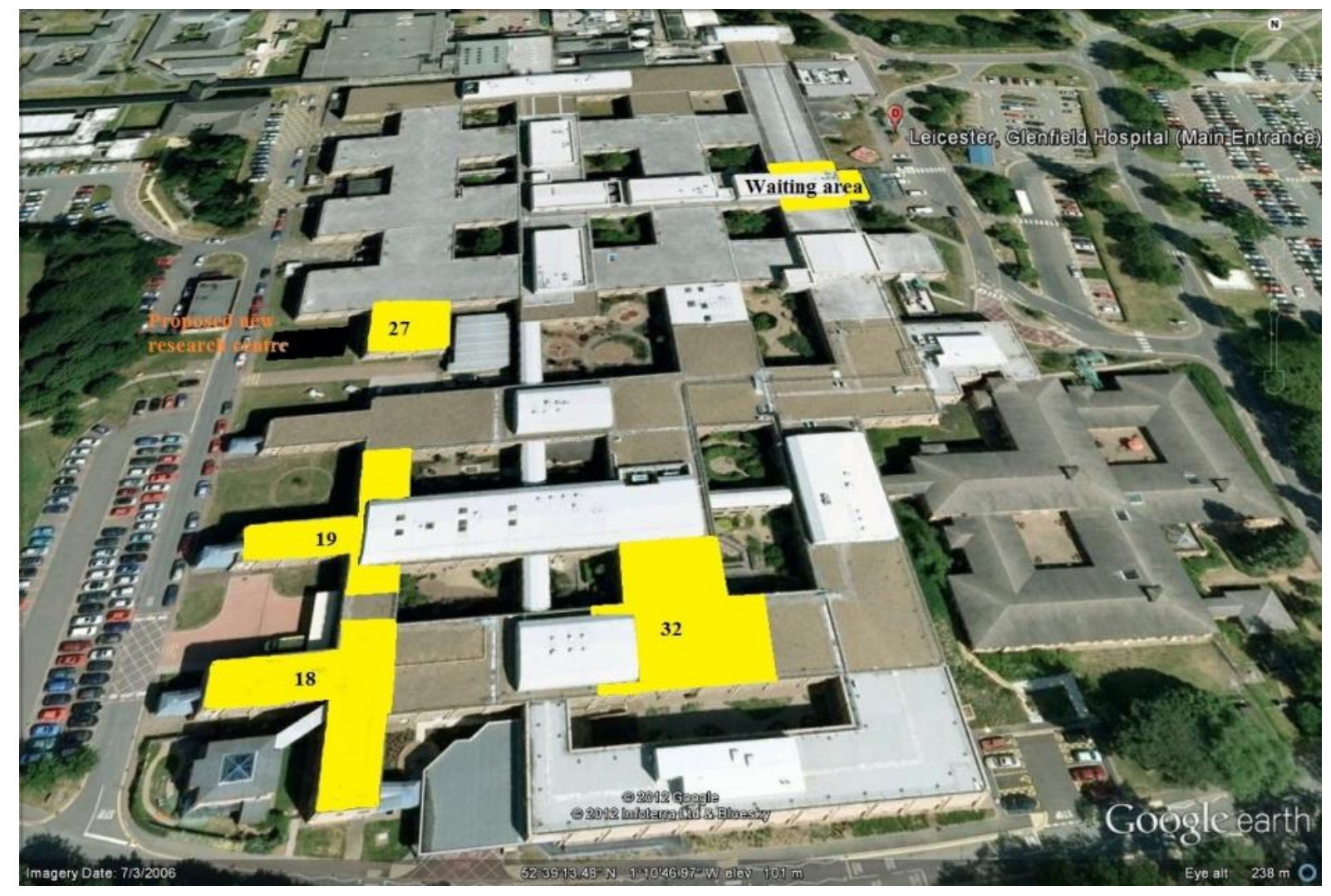

Fig.1: Aerialview of Glenfield Hospital (source: Google earth image modified [8]). The light shade (yellow) areas indicate the locations of the case study wards and the waiting area. The black patch is the proposed new research centre.

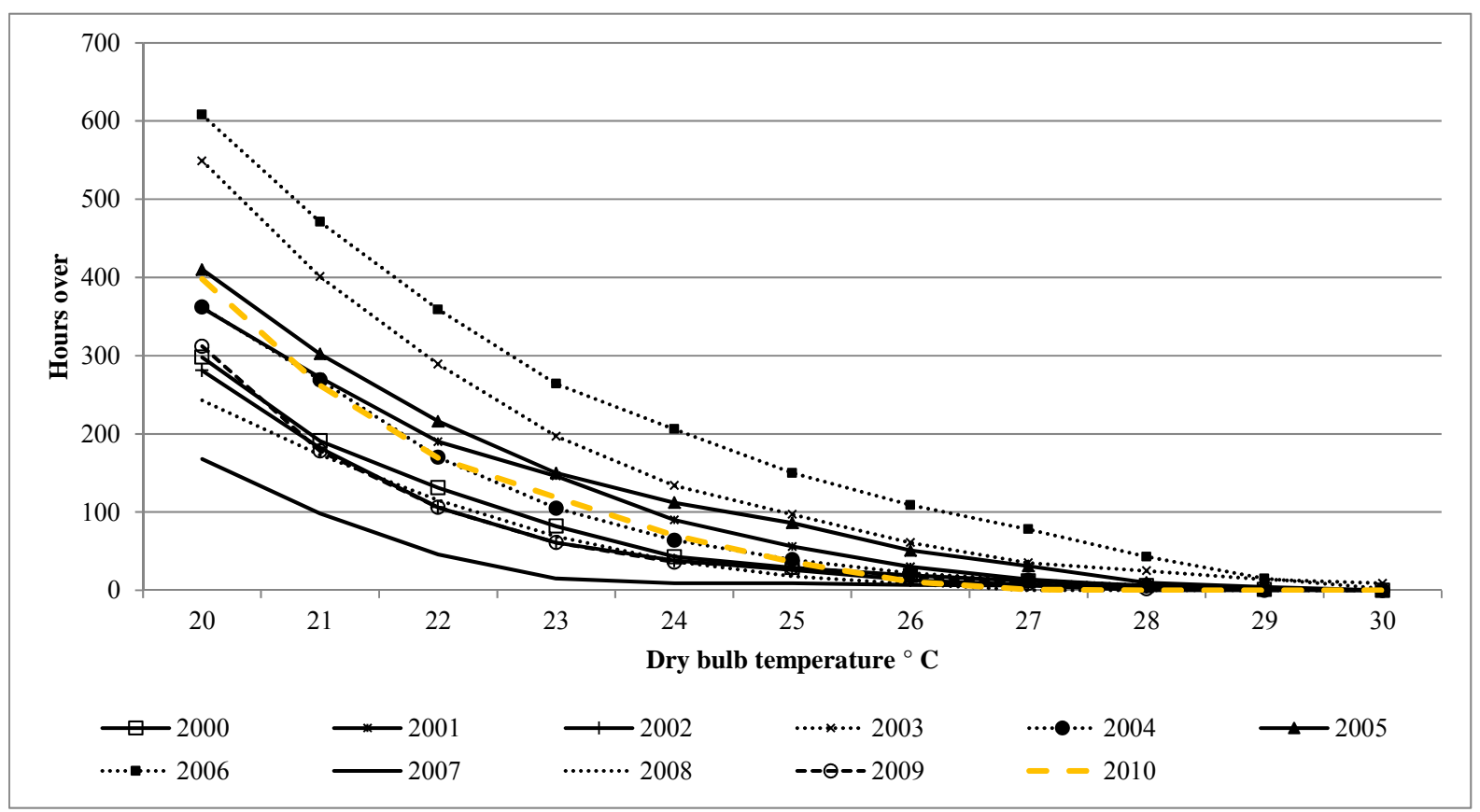


Fig.2: Frequency of occurrence of outdoor temperature between 2000 and 2010, Cottesmore, Rutland, Leicestershire, UK [14].

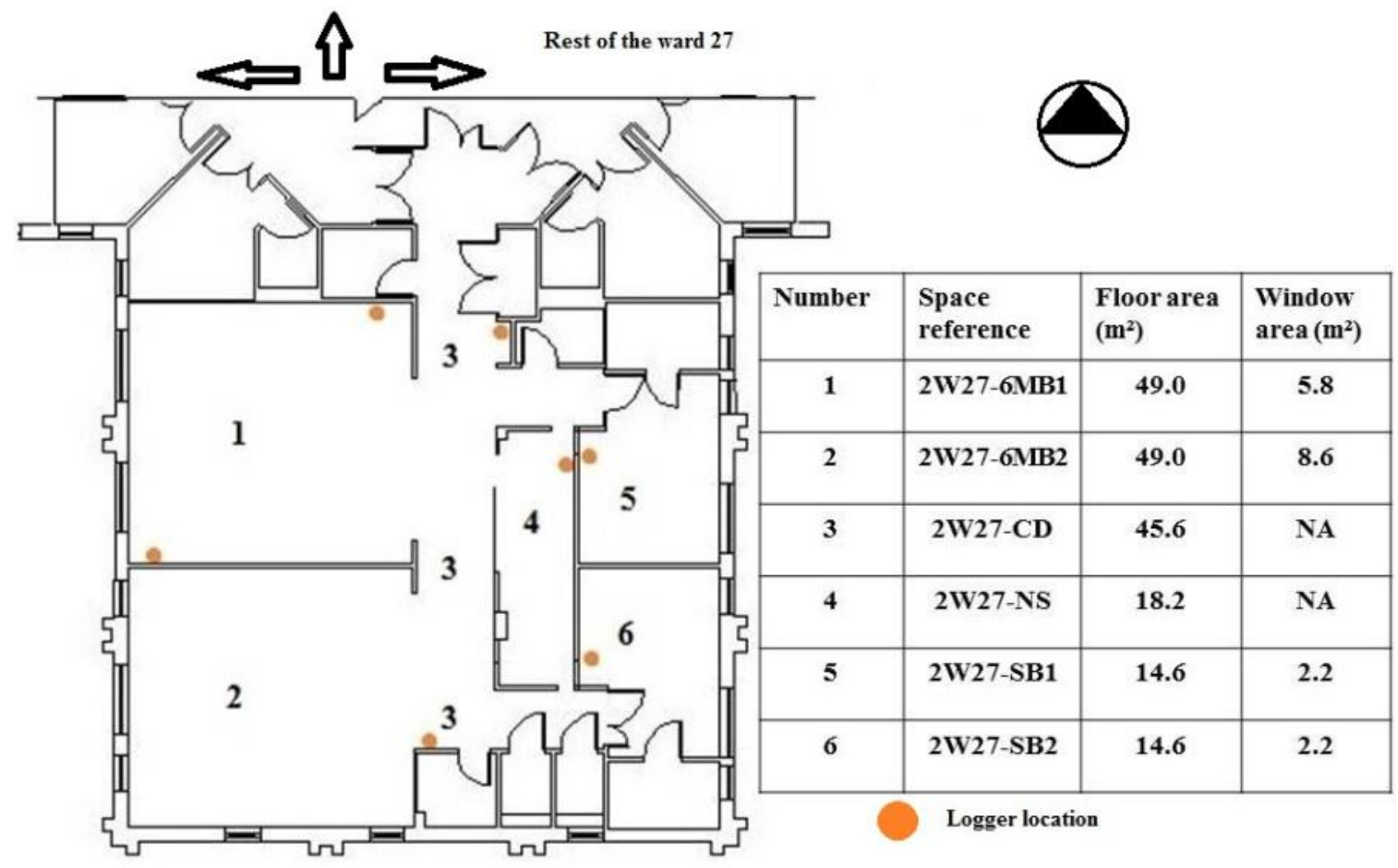

Fig. 3: Logger locations in ward 27 on the first floor. The multibed (MB) room 1 and 2 have 6 beds, room 5 and 6 are single bed.

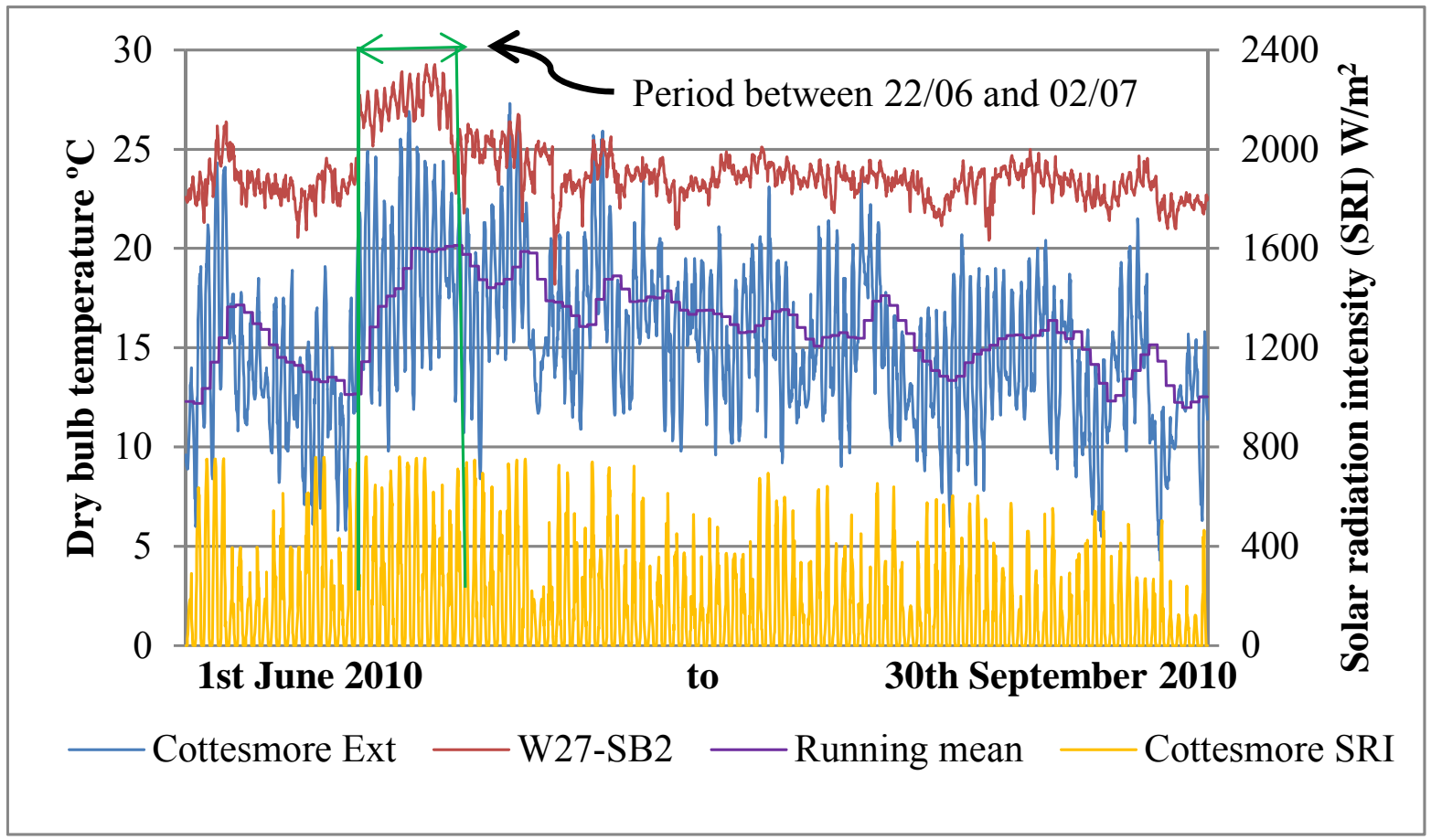


Fig. 4: Internal temperature in W27-SB2, external temperature, its running mean and solar radiation intensity.

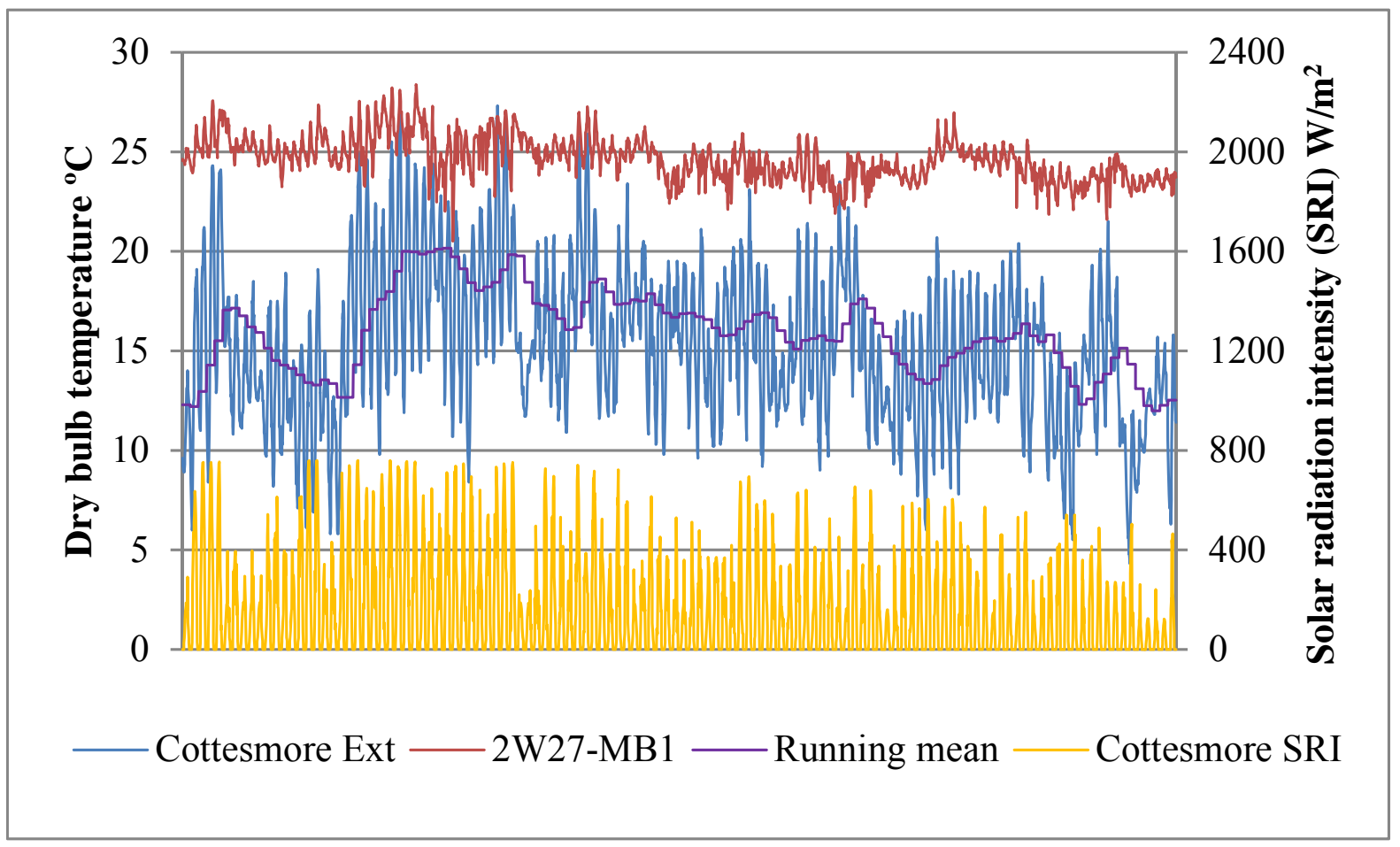

Fig. 5: Internal temperature in W27-MB1, external temperature, its running mean and solar radiation intensity.

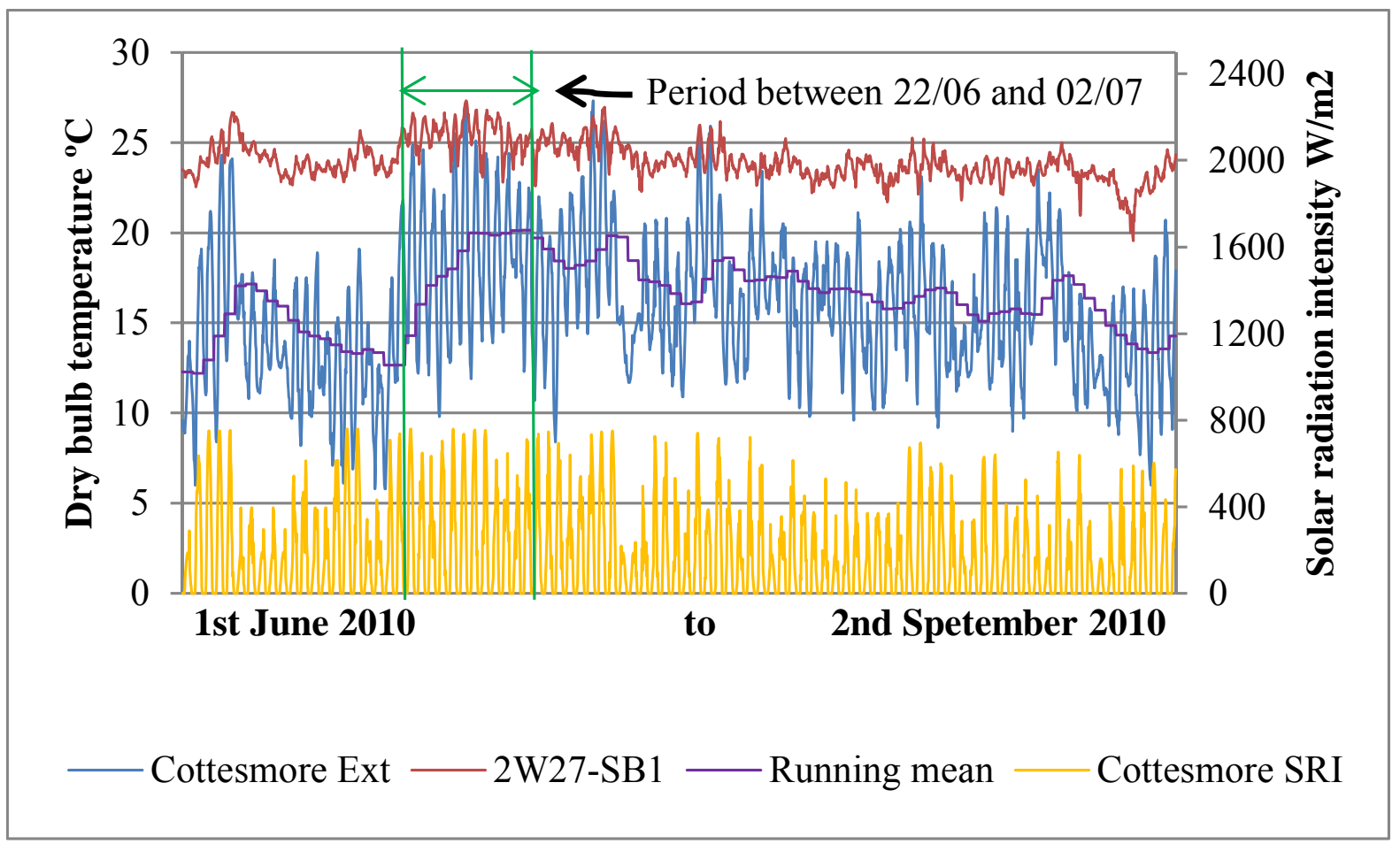


Fig. 6: Internal temperature in W27-SB1, external temperature, its running mean and solar radiation intensity.

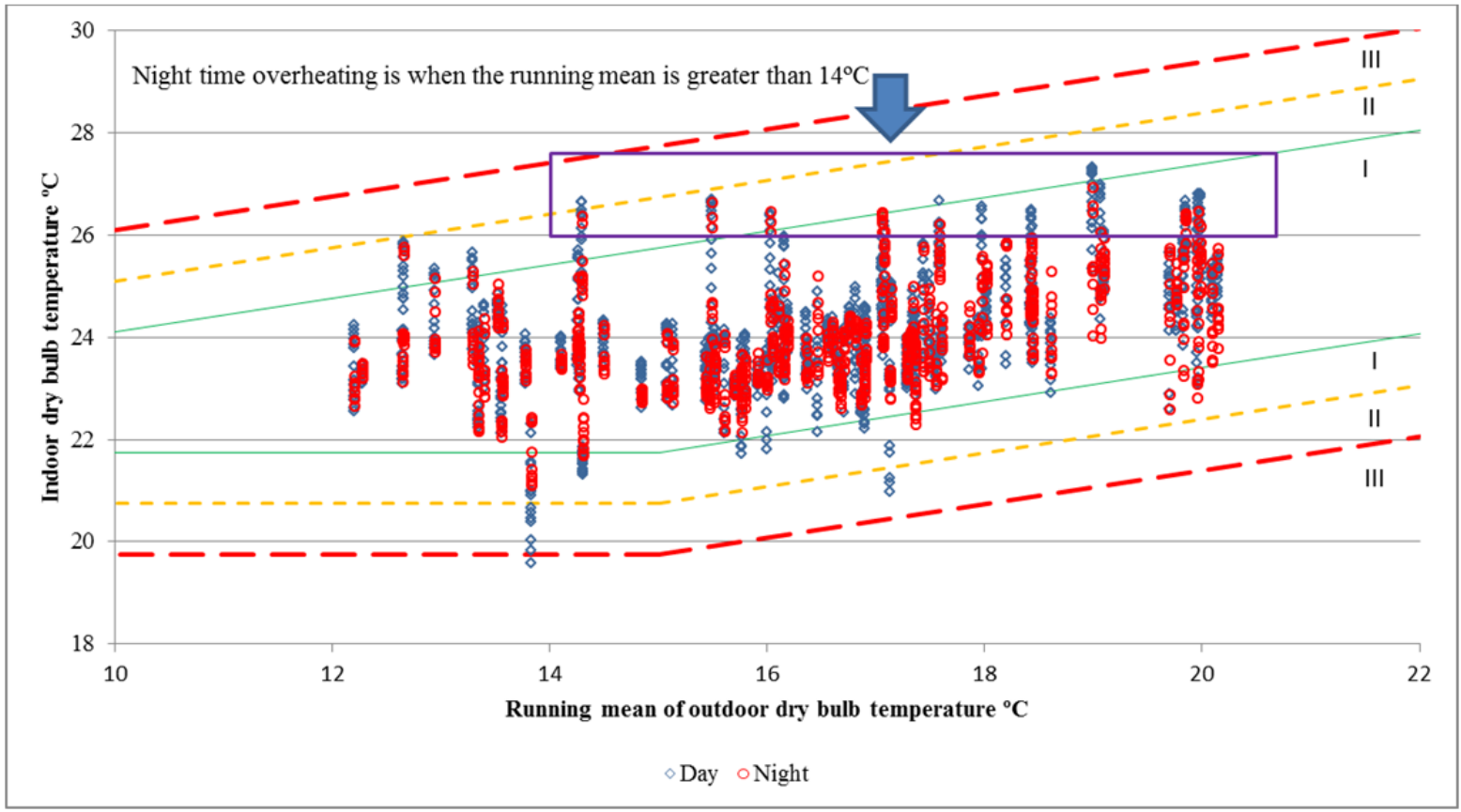

Fig. 7: Internal temperatures of 2W27-SB1 compared to BSEN15251 category limits.

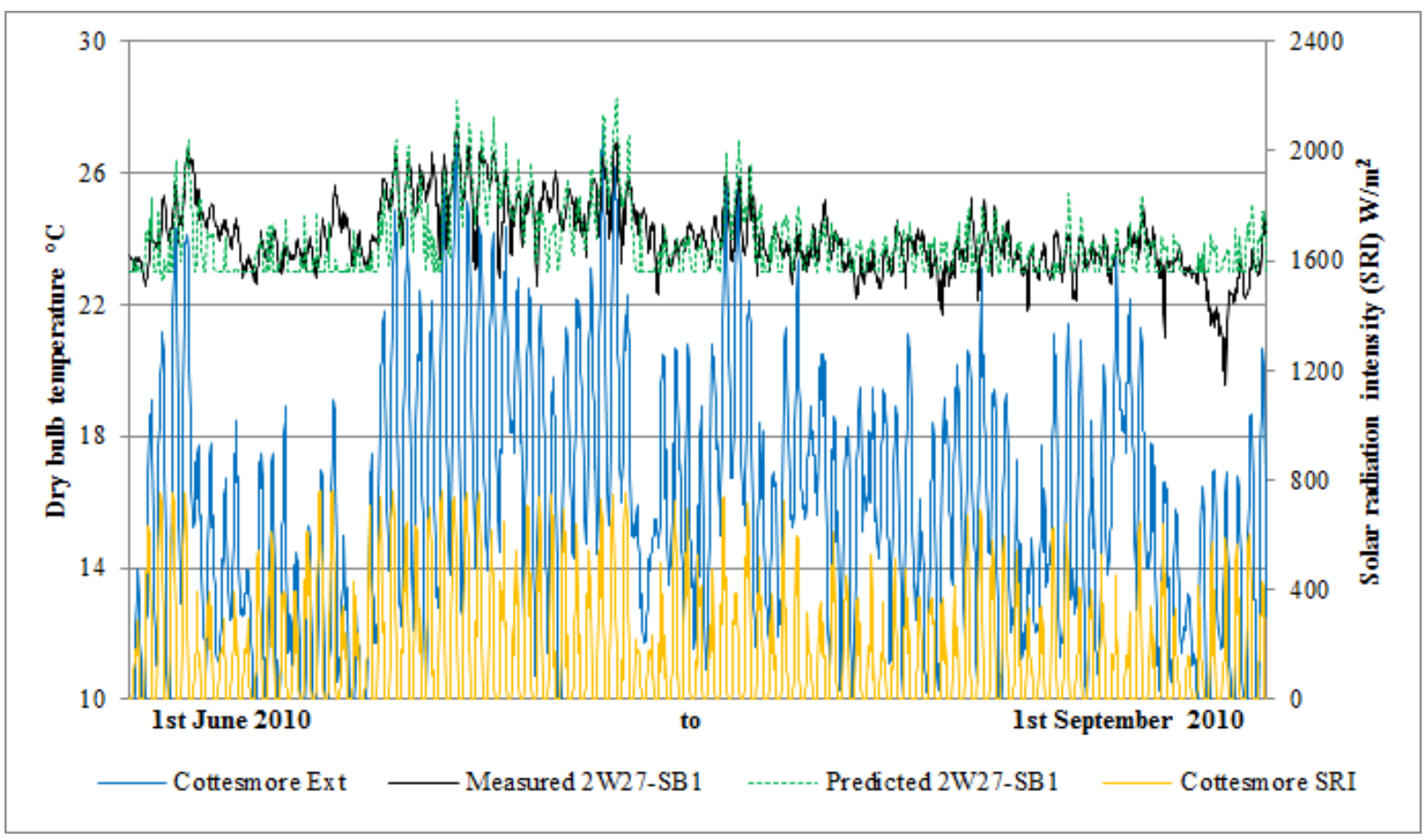

Fig. 8: Measured and predicted temperature in 2W27-SB1, external temperature, and solar radiation intensity for calibration period. 


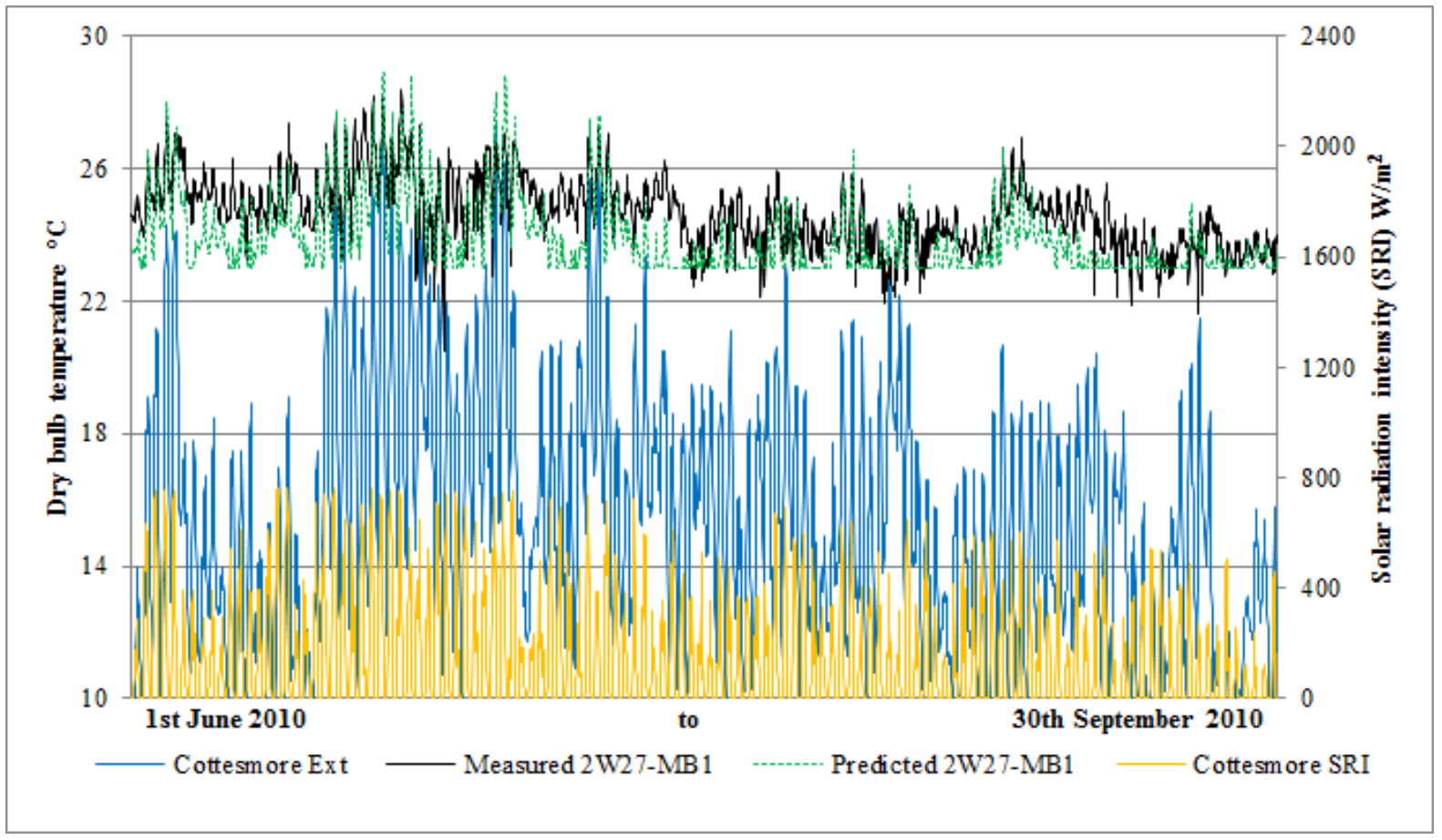

Fig. 9: Measured and predicted temperature in 2W27-MB1, external temperature, and solar radiation intensity for calibration period. 


\section{Tables}

Table 1: Criteria for assessing internal temperatures in naturally ventilated spaces [2].

\begin{tabular}{|c|c|c|c|c|}
\hline Assessment metric & Source & Criterion & Applicability & Comment \\
\hline $\begin{array}{l}\text { Total hours, dry-bulb } \\
\text { temperature over } 28^{\circ} \mathrm{C} .\end{array}$ & $\begin{array}{l}\text { HTM03-01 } \\
\quad[15]\end{array}$ & $\begin{array}{l}\text { Limiting value } 50 \\
\text { hours. }\end{array}$ & All spaces and buildings. & $\begin{array}{l}\text { Weather year to be used in } \\
\text { simulations not stated. }\end{array}$ \\
\hline $\begin{array}{l}\text { Night time hours operative } \\
\text { temperature over } 26^{\circ} \mathrm{C} .\end{array}$ & $\begin{array}{c}\text { CIBSE } \\
\text { Guide A } \\
{[17]}\end{array}$ & $\begin{array}{c}\text { No more than } 1 \% \\
\text { of hours above } \\
\text { value. }\end{array}$ & Sleeping spaces only. & $\begin{array}{l}\text { Value based on homes and } \\
\text { not health care facilities. }\end{array}$ \\
\hline $\begin{array}{l}\text { Adaptive comfort Cat. I } \\
\text { and Cat II envelopes. } \\
\text { Thresholds of operative } \\
\text { temperature vary with } \\
\text { running mean of ambient } \\
\text { temperature. }\end{array}$ & $\begin{array}{c}\text { BSEN15251 } \\
{[18]}\end{array}$ & $\begin{array}{l}\text { No more than } 5 \% \\
\text { of hours outside } \\
\text { envelope, in any } \\
\text { day, week, month } \\
\text { or year. }\end{array}$ & $\begin{array}{l}\text { Naturally ventilated } \\
\text { buildings with operable } \\
\text { windows and } \\
\text { mechanically ventilated } \\
\text { building without } \\
\text { conditioning the air. }\end{array}$ & $\begin{array}{c}\text { Cat I is applicable to spaces } \\
\text { with vulnerable individuals, } \\
\text { such as wards, Cat II for } \\
\text { 'normally' occupied spaces, } \\
\text { such as offices, consulting } \\
\text { rooms, etc. }\end{array}$ \\
\hline
\end{tabular}

1. The limiting value for a year is 50, 37 (night time) and 438 hours for HTM03-01, CIBSE and BSEN15251 respectively.

2. Between June and September 2010 , the outdoor temperatures were 724 and 356 hours above $18^{\circ} \mathrm{C}$ and $20^{\circ} \mathrm{C}$ respectively [14]. During this period fresh air was supplied to the rooms without heating and the perimeter heats were off (Table 3). General policy is to keep the perimeter heaters off from May to September [23]. However there could have been few occasional hours during the above said period where the room heaters could have been kept on based on individual preference. The results should be viewed keeping this limitation.

Table 2: Comparison of internal temperatures measured between 1st June and 30th September, 2010, with BSEN15251, CIBSE and HTM03 overheating criteria: Glenfield Hospital.

\begin{tabular}{|c|c|c|c|c|c|c|c|c|c|c|c|}
\hline $\begin{array}{l}\stackrel{0}{\pi} \\
\text { के }\end{array}$ & 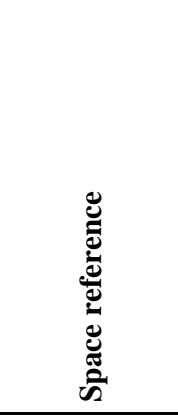 & 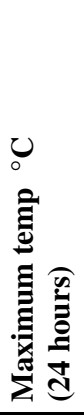 & 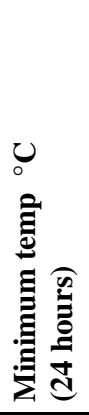 & 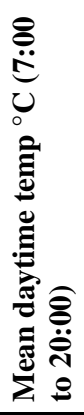 & 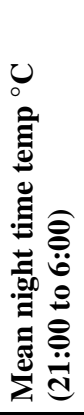 & בُ & 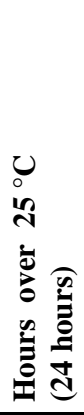 & 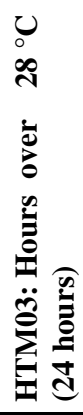 & 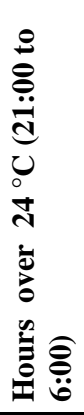 & 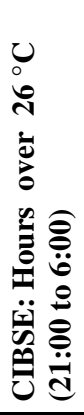 & 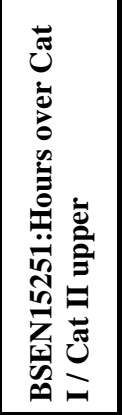 \\
\hline \multicolumn{12}{|l|}{ Ward 27, level 2} \\
\hline Corridor (CD) & 2W27-CD & 27.7 & 21.5 & 24.5 & 24.3 & 3.9 & 770 & 0 & 769 & NA & NA \\
\hline $\begin{array}{l}\text { Multi bedroom } 1 \\
\text { (MB1), 6beds }\end{array}$ & 2W27-6MB1 & 28.4 & 20.5 & 24.7 & 24.6 & 6.2 & 1050 & 7 & 859 & 110 & $255 / 60$ \\
\hline $\begin{array}{l}\text { Single bedroom } 1 \\
\text { (SB1) }\end{array}$ & 2W27-SB1 & 27.3 & 19.6 & 24.1 & 23.9 & 3.7 & 406 & 0 & 384 & 35 & $59 / 02$ \\
\hline $\begin{array}{c}\text { Single bedroom } 2 \\
\text { (SB2) }\end{array}$ & 2W27-SB2 & 29.3 & 18.2 & 23.9 & 23.7 & 5.0 & 455 & 70 & 348 & 112 & 206/ 102 \\
\hline Nurse station (NS) & 2W27-NS & 29.0 & 22.5 & 25.2 & 25.0 & 4.2 & 1419 & 57 & 936 & NA & NA \\
\hline
\end{tabular}

1. Total number of hours: 2928. Total number of night time (21:00 to 6:00) hours: 1220

2. For the space $2 \mathrm{~W} 27-\mathrm{SB} 1$, the monitored data is available for 2247 hours which includes 937 night time hours. Error in data after $2^{\text {nd }}$ September 14:00 hrs.

3. The space $2 \mathrm{~W} 27-6 \mathrm{MB} 2$ not monitored.

4. The limiting overheating values for the monitored period are: HTM03, 40 hours over $28^{\circ} \mathrm{C}$; BSEN15251, 147 hours above category upper threshold and CIBSE, 12 night time hours over $26^{\circ} \mathrm{C}$.

5. For the space $2 \mathrm{~W} 27-\mathrm{SB} 1$, the limiting overheating values are: $\mathrm{HTM} 03,31$ hours over $28^{\circ} \mathrm{C}$; BSEN15251, 113 hours above category upper threshold and CIBSE, 10 night time hours over $26^{\circ} \mathrm{C}$.

6. CIBSE night time condition is not applicable to nurse station corridors and waiting area since there is no provision for sleeping in these spaces.

7. Bold and italic values with grey shade: criterion limit exceeded 
Table 3: General construction information of Glenfield Hospital.

\begin{tabular}{|c|c|c|c|c|c|}
\hline Description & Material & $\begin{array}{c}\text { Thickness } \\
\text { (mm) }\end{array}$ & $\begin{array}{c}\text { Thermal } \\
\text { transmittance } \\
\left(\mathbf{W m}^{-2} \mathbf{K}^{-1}\right)\end{array}$ & $\begin{array}{l}\text { Opening size } \\
\text { (mm) }\end{array}$ & General information \\
\hline Wall & $\begin{array}{l}\text { Brick/cement } \\
\text { block }\end{array}$ & 300 & 0.4 & - & \multirow{4}{*}{$\begin{array}{l}\text { Total floor area of Ward } \\
27 \text { is } 1200 \mathrm{~m}^{2} \text {. The area } \\
\text { under investigation is } \\
216 \mathrm{~m}^{2} \text {. The floor to floor } \\
\text { height and floor to ceiling } \\
\text { height are } 3.9 \mathrm{~m} \text { and } 2.7 \\
\mathrm{~m} \text { respectively. The } \\
\text { window opening is } \\
\text { restricted to } 100 \mathrm{~mm} \text { for } \\
\text { patient safety [21]. }\end{array}$} \\
\hline Roof & $\begin{array}{c}\text { In-situ RCC } \\
\text { on steel } \\
\text { frame }\end{array}$ & 300 & 0.26 & - & \\
\hline Floor & $\begin{array}{c}\text { In-situ RCC } \\
\text { on steel } \\
\text { frame }\end{array}$ & 250 & 0.16 & - & \\
\hline Window & $\begin{array}{c}\text { Double } \\
\text { glazed } \\
\text { aluminium }\end{array}$ & - & 1.9 & $\begin{array}{c}1600 \mathrm{~mm} \times 1800 \mathrm{~mm} \text {, } \\
1600 \mathrm{~mm} \times 900 \mathrm{~mm} \\
\text { or } 800 \mathrm{~mm} \times 900 \mathrm{~mm}\end{array}$ & \\
\hline
\end{tabular}

Table 4: Model characteristics.

\begin{tabular}{|c|c|c|c|c|c|c|}
\hline Description & 2W27-SB1 & 2W27-SB2 & 2W27-MB1 & 2W27-MB2 & 2W27-NS & 2W27-CD \\
\hline External wall area $\left(\mathrm{m}^{2}\right)$ & 13.2 & 13.2 & 18.2 & 37.4 & NA & NA \\
\hline Floor area $\left(\mathrm{m}^{2}\right)$ & 14.6 & 14.6 & 49.0 & 49.0 & 18.2 & 45.6 \\
\hline Volume $\left(\mathrm{m}^{3}\right)$ & 39.5 & 39.5 & 132.3 & 132.3 & 49.1 & 115.0 \\
\hline Window area $\left(\mathrm{m}^{2}\right)$ & 2.2 & 2.2 & 5.8 & 8.6 & NA & NA \\
\hline $\begin{array}{l}\text { Internal heat gain } \\
\left(\mathrm{W} / \mathrm{m}^{2}\right)\end{array}$ & 5.4 to 15.1 & 5.4 to 15.1 & 8.6 to 19.6 & 8.6 to 19.6 & 54 to 65 & 0.7 to 4.4 \\
\hline Perimeter heating & Yes & Yes & Yes & Yes & NO & $\mathrm{NO}$ \\
\hline $\begin{array}{l}\text { Window opening } \\
\text { strategy }\end{array}$ & \multicolumn{4}{|c|}{$\begin{array}{l}\text { The occupants were assumed to open the windows. The maximum } \\
\text { opening is } 100 \mathrm{~mm} \text {. The opening area assumed to be } 0 \% \text { if the } \mathrm{T}_{\text {out }} \leq \\
10^{\circ} \mathrm{C} \text {, and } 50 \% \text { if } \mathrm{T}_{\text {out }}>10^{\circ} \mathrm{C} \text { and } \mathrm{T}_{\text {in }} \leq 18^{\circ} \mathrm{C} \text {, then ramps up to } 100 \% \\
\text { at } \mathrm{T}_{\text {in }} \geq 20^{\circ} \mathrm{C}\end{array}$} & NA & NA \\
\hline $\begin{array}{l}\text { Perimeter heating } \\
\text { regime }\end{array}$ & \multicolumn{4}{|c|}{$\begin{array}{l}\text { Set point temperature is } 23^{\circ} \mathrm{C} \text {. Set point is } 100 \% \text { at } \mathrm{T}_{\text {out }}<-3^{\circ} \mathrm{C} \text { and it } \\
\text { ramps down to } 80 \% \text { at } \mathrm{T}_{\text {out }}=16^{\circ} \mathrm{C} \text {. It is off at } \mathrm{T}_{\text {out }}=20^{\circ} \mathrm{C} \text {. }\end{array}$} & NA & NA \\
\hline $\begin{array}{l}\text { Ventilation heating } \\
\text { regime }\end{array}$ & \multicolumn{6}{|c|}{$\begin{array}{l}\text { Continuous supply of fresh air at the rate of } 135 \mathrm{l} / \mathrm{s} \text { for the area under study. There is only one } \\
\text { supply grille and it is located on the nurse station ceiling. Supply air is heated to } 18^{\circ} \mathrm{C} \text {. Set-point } \\
\text { ramped down from } 100 \% \text { at } \mathrm{T}_{\text {out }} \leq 16^{\circ} \mathrm{C} \text { to zero at } \mathrm{T}_{\text {out }} \geq 18^{\circ} \mathrm{C} \text {. }\end{array}$} \\
\hline Extract regime & \multicolumn{6}{|c|}{$\begin{array}{l}\text { There are four toilets in this area. Each toilet has the facility to extract } 25 \mathrm{l} / \mathrm{s} \text { continuously. The } \\
\text { balance supplied air }(35 \mathrm{l} / \mathrm{s}) \text { escapes through windows. }\end{array}$} \\
\hline Occupancy & \multicolumn{6}{|c|}{$\begin{array}{l}\text { Maximum staff members at nurse station were } 6 \text {. In addition, between 7:00 and 9:00, and 18:00 } \\
\text { and 20:00 at every hour there were two staff members at each of the multi bedroom and one staff } \\
\text { member at each of the single bedrooms for five minutes. The rest of the time at every hour there } \\
\text { was one staff member at each of the single and multi-bedrooms. }\end{array}$} \\
\hline
\end{tabular}


Table 5: Comparison of measured and predicted results of ward 27 for the calibration period.

\begin{tabular}{|c|c|c|c|c|c|c|c|c|}
\hline 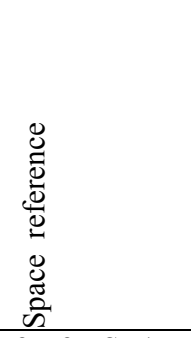 & & 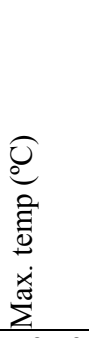 & 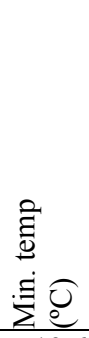 & 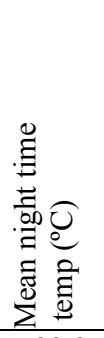 & 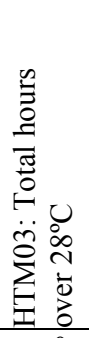 & 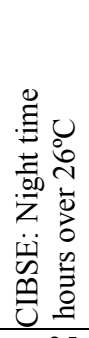 & 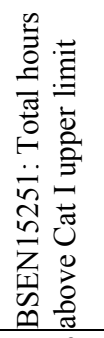 & 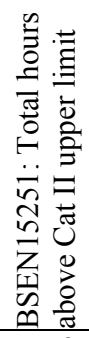 \\
\hline \multirow[t]{2}{*}{ 2W27-SB1 } & Measured & 27.3 & 19.6 & 23.9 & 0 & 35 & 59 & 2 \\
\hline & Predicted & 28.3 & 22.7 & 23.5 & 4 & 24 & 61 & 3 \\
\hline \multirow{2}{*}{ 2W27-6MB1 } & Measured & 28.4 & 20.5 & 24.6 & 6 & 98 & 305 & 71 \\
\hline & Predicted & 28.9 & 23.0 & 23.8 & 16 & 51 & 163 & 52 \\
\hline \multirow{2}{*}{ 2W27-NS } & Measured & 29.0 & 22.5 & 25.0 & 57 & $\mathrm{NA}$ & NA & $\overline{\mathrm{NA}}$ \\
\hline & Predicted & 29.4 & 24.3 & 25.1 & 49 & NA & NA & $\mathrm{NA}$ \\
\hline
\end{tabular}

Notes (Table 5):

1. Calibration period for MB1 and NS is $1^{\text {st }}$ June to $30^{\text {th }}$ September 2010.

2. Calibration period for SB1 is $1^{\text {st }}$ June to $2^{\text {nd }}$ September 2010.

Table 6: Summary of predicted performance of Ward 27 during the summer of 2010.

\begin{tabular}{|c|c|c|c|c|c|c|c|c|c|}
\hline 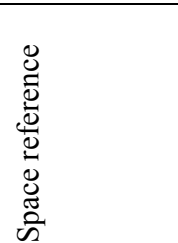 & 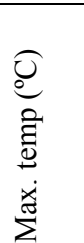 & 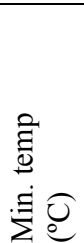 & 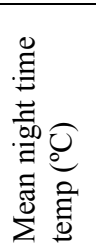 & 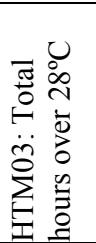 & 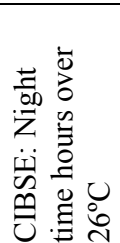 & 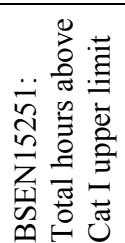 & 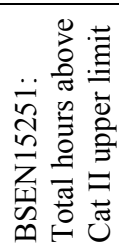 & 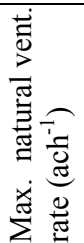 & 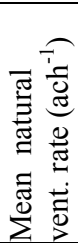 \\
\hline 2W27-SB1 & 28.1 & 22.9 & 23.5 & 4 & 25 & 148 & 20 & 30 & 2.3 \\
\hline 2W27-SB2 & 28.1 & 22.9 & 23.4 & 4 & 22 & 140 & 17 & 30 & 2.3 \\
\hline 2W27-6MB1 & 29.1 & 22.9 & 23.8 & 18 & 55 & 289 & 94 & 7 & 1.2 \\
\hline 2W27-6MB2 & 29.0 & 22.8 & 23.5 & 11 & 32 & 265 & 89 & 15 & 3.5 \\
\hline 2W27-NS & 29.4 & 24.7 & 25.4 & 53 & NA & NA & NA & - & - \\
\hline 2W27-CD & 28.1 & 23.1 & 23.8 & 3 & NA & NA & $\mathrm{NA}$ & - & - \\
\hline
\end{tabular}

Notes (Table 6):

1. The HTM03 threshold is based on dry bulb temperature and rest are based on dry resultant temperature.

2. CIBSE night time condition is not applicable to nurse station and corridors since there is no provision for sleeping.

3. BSEN15251 conditions are applicable only to spaces with operable windows.

4. It is assumed that during the period of October to April the spaces will not overheat due to elevated ambient temperature and solar gains. Therefore the limiting overheating values are: HTM03, 50 hours over $28^{\circ} \mathrm{C}$; BSEN15251, 438 hours above category upper threshold and CIBSE, 37 night time hours over $26^{\circ} \mathrm{C}$. 
Table 7: Summary of predicted performance of ward 27 for current and future, test reference (TRY) and design summer (DSY) years.

\begin{tabular}{|c|c|c|c|c|c|c|c|c|c|c|c|c|c|c|c|c|}
\hline \multirow{2}{*}{ 串 } & \multirow{2}{*}{ 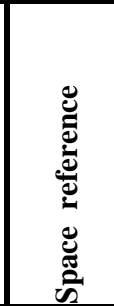 } & \multirow[b]{2}{*}{ ્ֻટ } & \multicolumn{2}{|c|}{ 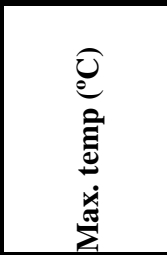 } & \multicolumn{2}{|c|}{ 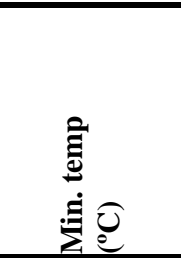 } & \multicolumn{2}{|c|}{ 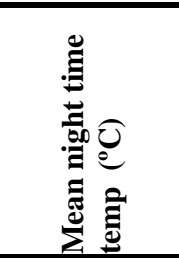 } & \multicolumn{2}{|c|}{ 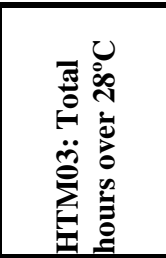 } & \multicolumn{2}{|c|}{ 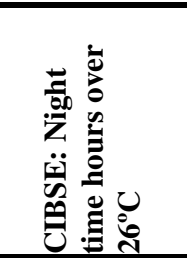 } & \multicolumn{2}{|c|}{ 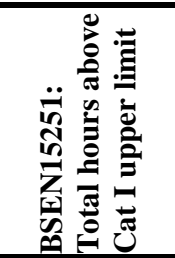 } & \multicolumn{2}{|c|}{ 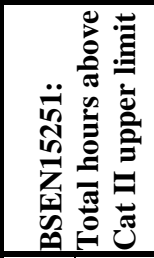 } \\
\hline & & & TRY & DSY & TRY & DSY & TRY & DSY & TRY & $D S Y$ & TRY & $D S Y$ & TRY & DSY & TRY & DSY \\
\hline \multirow{10}{*}{ 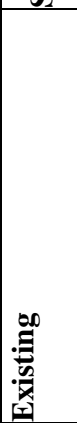 } & \multirow{3}{*}{$\begin{array}{l}\text { 2W27- } \\
\text { SB1 }\end{array}$} & 05 & 27.5 & 28.4 & 22.8 & 22.7 & 23.4 & 23.5 & 0 & 7 & 10 & 30 & 154 & 108 & 4 & 6 \\
\hline & & $30 \mathrm{~s}$ & 28.9 & 31.6 & 22.6 & 22.8 & 23.9 & 25.3 & 26 & 559 & 72 & 557 & 257 & 870 & 56 & 334 \\
\hline & & $50 \mathrm{~s}$ & 30.8 & 33.2 & 22.7 & 22.6 & 24.5 & 26.0 & 168 & 935 & 225 & 745 & 556 & 1224 & 129 & 631 \\
\hline & \multirow{3}{*}{$\begin{array}{l}\text { 2W27- } \\
6 \mathrm{MB} 1\end{array}$} & 05 & 29.2 & 30.5 & 22.9 & 22.9 & 23.9 & 23.9 & 19 & 40 & 53 & 81 & 387 & 255 & 119 & 65 \\
\hline & & $30 \mathrm{~s}$ & 30.5 & 32.5 & 22.9 & 23.0 & 24.4 & 25.9 & 80 & 775 & 167 & 707 & 469 & 1129 & 169 & 602 \\
\hline & & $50 \mathrm{~s}$ & 32.1 & 34.2 & 22.9 & 22.9 & 25.2 & 26.7 & 348 & 1147 & 424 & 893 & 897 & 1514 & 421 & 879 \\
\hline & & & & & & & & & & & & & & & & \\
\hline & \multirow{3}{*}{$\begin{array}{l}\text { 2W27- } \\
\text { NS }\end{array}$} & 05 & 29.3 & 30.5 & 24.8 & 24.7 & 25.5 & 25.5 & 49 & 78 & NA & $N A$ & NA & $N A$ & NA & $N A$ \\
\hline & & $30 \mathrm{~s}$ & 30.6 & 33.2 & 24.8 & 24.8 & 26.0 & 27.4 & 180 & 1254 & NA & $N A$ & NA & $N A$ & NA & $N A$ \\
\hline & & $50 \mathrm{~s}$ & 32.5 & \begin{tabular}{|l|}
34.8 \\
\end{tabular} & 24.8 & 24.7 & 26.7 & 28.2 & 595 & 1662 & NA & $N A$ & NA & $N A$ & NA & NA \\
\hline \multirow{10}{*}{ 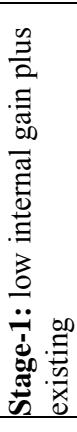 } & \multirow{3}{*}{$\begin{array}{l}\text { 2W27- } \\
\text { SB1 }\end{array}$} & 05 & 27.1 & 28.1 & 22.6 & 22.6 & 23.3 & 23.4 & 0 & 3 & 4 & 17 & 73 & 36 & 2 & 0 \\
\hline & & $30 \mathrm{~s}$ & 28.6 & 31.1 & 22.5 & 22.7 & 23.7 & 24.9 & 11 & 393 & 31 & 433 & 110 & 562 & 25 & 175 \\
\hline & & $50 \mathrm{~s}$ & 30.1 & 32.6 & 22.5 & 22.5 & 24.2 & 25.6 & 97 & 740 & 158 & 610 & 280 & 868 & 69 & 365 \\
\hline & \multirow{3}{*}{$\begin{array}{l}\text { 2W27- } \\
6 \mathrm{MB} 1\end{array}$} & 05 & 28.7 & 30.0 & 22.9 & 22.9 & 23.6 & 23.6 & 6 & 18 & 24 & 46 & 252 & 153 & 57 & 42 \\
\hline & & $30 \mathrm{~s}$ & 29.9 & 32.1 & 22.9 & 22.9 & 24.0 & 25.4 & 43 & 557 & 78 & 571 & 303 & 804 & 101 & 404 \\
\hline & & $50 \mathrm{~s}$ & 31.4 & 33.7 & 22.9 & 22.9 & 24.7 & 26.1 & 215 & 908 & 266 & 777 & 623 & 1125 & 243 & 598 \\
\hline & & & & & & & & & & & & & & & & \\
\hline & \multirow{3}{*}{$\begin{array}{l}\mathrm{W} 27- \\
\mathrm{NS}\end{array}$} & 05 & 28.2 & 29.4 & 23.9 & 23.9 & 24.6 & 24.6 & 6 & 26 & NA & $N A$ & NA & $N A$ & NA & $N A$ \\
\hline & & $30 \mathrm{~s}$ & 29.4 & 31.9 & 23.9 & 23.9 & 25.0 & 26.3 & 52 & 748 & NA & $N A$ & NA & $N A$ & NA & $N A$ \\
\hline & & $50 \mathrm{~s}$ & 31.1 & 33.6 & 23.9 & 23.9 & 25.6 & 27.0 & 292 & 1140 & NA & $N A$ & NA & $N A$ & NA & $N A$ \\
\hline \multirow{9}{*}{ 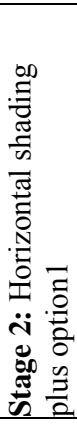 } & 2W27- & 05 & 26.3 & 27.8 & 22.3 & 22.4 & 23.2 & 23.2 & 0 & 1 & 0 & 9 & 16 & 10 & 0 & 0 \\
\hline & SB1 & $30 \mathrm{~s}$ & 28.2 & 30.4 & 22.4 & 22.5 & 23.4 & 24.5 & 4 & 232 & 12 & 303 & 33 & 226 & 4 & 62 \\
\hline & & $50 \mathrm{~s}$ & 28.9 & 31.9 & 22.3 & 22.3 & 23.9 & 25.2 & 38 & 503 & 102 & 477 & 88 & 452 & 19 & 130 \\
\hline & 2W27- & 05 & 27.8 & 29.1 & 22.9 & 22.9 & 23.4 & 23.5 & 0 & 6 & 4 & 20 & 89 & 59 & 6 & 11 \\
\hline & $6 \mathrm{MB} 1$ & $30 \mathrm{~s}$ & 28.8 & 31.3 & 22.9 & 22.9 & 23.8 & 25.0 & 9 & 357 & 33 & 461 & 130 & 483 & 29 & 187 \\
\hline & & $50 \mathrm{~s}$ & 30.1 & 33.1 & 22.9 & 22.9 & 24.3 & 25.7 & 98 & 671 & 176 & 612 & 285 & 741 & 70 & 312 \\
\hline & $2 \mathrm{~W} 27-$ & 05 & 27.5 & 28.8 & 23.9 & 23.9 & 24.4 & 24.4 & 0 & 10 & NA & $N A$ & NA & $N A$ & NA & $N A$ \\
\hline & & $30 \mathrm{~s}$ & 28.8 & 31.4 & 23.9 & 23.9 & 24.7 & 25.9 & 16 & 526 & NA & $N A$ & NA & $N A$ & NA & $N A$ \\
\hline & & $50 \mathrm{~s}$ & 30.1 & 33.0 & 23.9 & 23.9 & 25.2 & 26.6 & 163 & 907 & NA & $N A$ & NA & $N A$ & NA & NA \\
\hline & 2W27- & 05 & 26.0 & 26.6 & 22.3 & 22.4 & 23.2 & 23.2 & NA & $N A$ & 0 & 0 & 14 & 1 & 0 & 0 \\
\hline & SB1 & $30 \mathrm{~s}$ & 27.0 & 29.2 & 22.4 & 22.5 & 23.4 & 24.3 & NA & $N A$ & 1 & 123 & 15 & 48 & 0 & 5 \\
\hline$\stackrel{0}{2}$ & & $50 \mathrm{~s}$ & 27.7 & 30.7 & 22.3 & 22.3 & 27.4 & 24.8 & NA & $N A$ & 22 & 290 & 17 & 104 & 0 & 26 \\
\hline$=0$ & 2W27- & 05 & 26.6 & 27.9 & 22.9 & 22.9 & 23.4 & 23.5 & NA & $N A$ & 0 & 6 & 58 & 26 & 4 & 1 \\
\hline च & $6 \mathrm{MB} 1$ & $30 \mathrm{~s}$ & 27.6 & 30.1 & 22.9 & 22.9 & 23.7 & 24.6 & NA & $N A$ & 4 & 204 & 56 & 152 & 4 & 28 \\
\hline 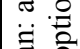 & & $50 \mathrm{~s}$ & 28.9 & 31.9 & 22.9 & 22.9 & 24.2 & 25.2 & NA & $N A$ & 67 & 380 & 85 & 257 & 10 & 88 \\
\hline $\mid \begin{array}{ll}\pi & 0 \\
1 & 0\end{array}$ & & & & & & & & & & & & & & & & \\
\hline$\ddot{n} \frac{\partial}{2}$ & 2W27- & 05 & 26.3 & 27.6 & 23.9 & 23.9 & 24.4 & 24.4 & NA & $N A$ & NA & $N A$ & NA & $N A$ & NA & $N A$ \\
\hline 巳ي & NS & $30 \mathrm{~s}$ & 27.6 & 30.2 & 23.9 & 23.9 & 24.6 & 25.4 & NA & $N A$ & NA & $N A$ & NA & $N A$ & NA & $N A$ \\
\hline 䨔 & & $50 \mathrm{~s}$ & 28.9 & 31.8 & 23.9 & 23.9 & 25.0 & 25.9 & NA & $N A$ & NA & $N A$ & NA & $N A$ & NA & NA \\
\hline 1. & & & enres & $\overline{\text { nt } 20}$ & ceurr & and & $30 \mathrm{~s}$ & $\overline{205}$ & res & tive & & & & & & \\
\hline 2. & The HT & 03 & hol & ba & 10 & & per & an & est & & & ulta & & Ire. & & \\
\hline 3. & $\begin{array}{l}\text { CIBSE } \\
\text { these sp }\end{array}$ & ht & $\mathrm{col}$ & dition & ot a & cabl & nur & tatic & and & rrido & ince & re is & prov & on $\mathrm{fc}$ & 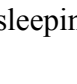 & in \\
\hline
\end{tabular}


5. HTM03 standard not applicable for fans.

6. Night time hours are 21:00 to 6:00.

7. Simulated hours (3672) are for May to September.

8. It is assumed that during the period of October to April the spaces will not overheat due to elevated ambient temperature and solar gains. Therefore the limiting overheating values are: HTM03, 50 hours over $28^{\circ} \mathrm{C}$; BSEN15251, 438 hours above category upper threshold and CIBSE, 37 night time hours over $26^{\circ} \mathrm{C}$.

9. Un-shaded values indicate that they are within the threshold limit, dark grey shade indicate that the exceedance is substantial, and light grey shade indicates exceedance is minor. 
Appendix A: Comparison of internal temperatures measured between 1st June and 30th September, 2010, with BSEN15251, CIBSE and HTM03 overheating criteria: In Ward 18, 19 and 32, and main waiting area at Glenfield Hospital.

\begin{tabular}{|c|c|c|c|c|c|c|c|c|c|c|c|}
\hline $\begin{array}{l}\stackrel{\tilde{\Xi}}{0} \\
\text { के }\end{array}$ & 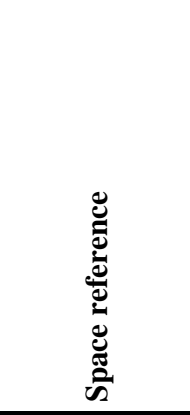 & 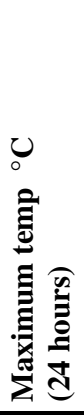 & 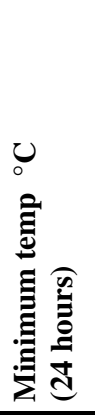 & 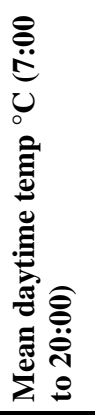 & 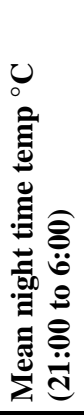 & 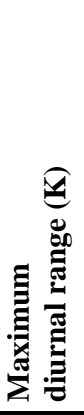 & 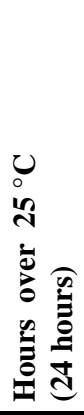 & 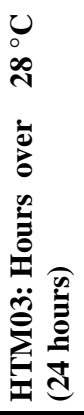 & 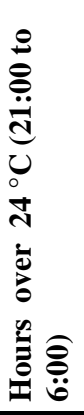 & 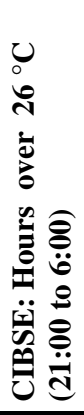 & 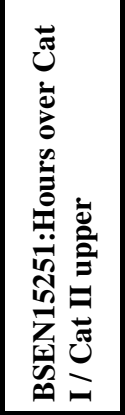 \\
\hline $\begin{array}{c}\text { Main Waiting area } \\
\text { (WA) }\end{array}$ & $1 \mathrm{WA}$ & 26.9 & 20.2 & 23.9 & 24.1 & 3.6 & 442 & 0 & 678 & NA & $13 / 0$ \\
\hline \multicolumn{12}{|l|}{ Ward 18, level 1} \\
\hline $\begin{array}{c}\text { Open ward (OW), } 22 \\
\text { beds }\end{array}$ & 1W18-22OW & 26.6 & 20.0 & 23.8 & 23.3 & 4.3 & 182 & 0 & 243 & 0 & $45 / 1$ \\
\hline Nurse station(NS) & $1 \mathrm{~W} 18-\mathrm{NS}$ & 28.9 & 21.4 & 25.4 & 24.7 & 4.3 & 1617 & 2 & 1017 & NA & $462 / 103$ \\
\hline \multicolumn{12}{|l|}{ War19, level 1} \\
\hline $\begin{array}{l}\text { Open ward (OW), } 24 \\
\text { beds }\end{array}$ & 1W19-24OW & 26.8 & 20.3 & 23.8 & 23.5 & 4.3 & 284 & 0 & 330 & 2 & $106 / 2$ \\
\hline Nurse station (NS) & 1W19-NS & 27.8 & 22.1 & 24.2 & 24.0 & 3.8 & 290 & 0 & 625 & NA & $86 / 0$ \\
\hline \multicolumn{12}{|l|}{ Ward32, level 2} \\
\hline Corridor (CD) & $2 \mathrm{~W} 32-\mathrm{CD}$ & 28.0 & 21.9 & 24.5 & 24.2 & 3.8 & 718 & 2 & 712 & NA & NA \\
\hline $\begin{array}{l}\text { Multi bedroom } 1 \\
\text { (MB1), } 4 \text { beds }\end{array}$ & 2W32-4MB1 & 28.3 & 22.2 & 25.1 & 24.8 & 3.2 & 1326 & 6 & 950 & 158 & $244 / 33$ \\
\hline $\begin{array}{l}\text { Multi bedroom } 2 \\
\text { (MB2), } 4 \text { beds }\end{array}$ & 2W32-4MB2 & 28.0 & 21.5 & 24.8 & 24.6 & 3.8 & 997 & 0 & 906 & 94 & $166 / 8$ \\
\hline $\begin{array}{l}\text { Multi bedroom } 3 \\
\text { (MB3), 4beds }\end{array}$ & 2W32-4MB3 & 28.6 & 20.5 & 25.2 & 25.0 & 4.8 & 1547 & 14 & 1049 & 187 & $397 / 58$ \\
\hline $\begin{array}{l}\text { Single bedroom } 1 \\
\text { (SB1) }\end{array}$ & 2W32-SB1 & 28.3 & 21.0 & 24.5 & 24.4 & 2.8 & 838 & 4 & 712 & 177 & $253 / 39$ \\
\hline $\begin{array}{c}\text { Single bedroom } 2 \\
\text { (SB2) }\end{array}$ & 2W32-SB2 & 28.6 & 20.5 & 24.7 & 24.7 & 3.2 & 1017 & 26 & 885 & 193 & $280 / 60$ \\
\hline Nurse station (NS) & $2 \mathrm{~W} 32-\mathrm{NS}$ & 28.0 & 21.9 & 24.8 & 24.5 & 3.9 & 1062 & 1 & 889 & NA & NA \\
\hline
\end{tabular}

Notes (Appendix A):

1. Total number of hours: 2928. Total number of night time (21:00 to 6:00) hours: 1220

2. The limiting overheating values for the monitored period are: HTM03, 40 hours over $28^{\circ} \mathrm{C}$; BSEN15251, 147 hours above category upper threshold and CIBSE, 12 night time hours over $26^{\circ} \mathrm{C}$.

3. CIBSE night time condition is not applicable to nurse station corridors and waiting area since there is no provision for sleeping in these spaces.

4. BSEN15251 conditions are applicable only to spaces with operable windows. Nurse station in open wards (OW) benefit from operable windows since they are open islands in the wards.

5. Bold and italic values with grey shade: criterion limit exceeded. 
Appendix B: Summary of predicted performance of Ward 27 during the summer of 2010 with enhanced air supply (205 l/s).

\begin{tabular}{|c|c|c|c|c|c|c|c|}
\hline Space & 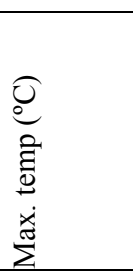 & 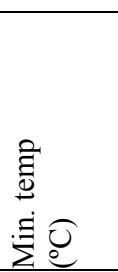 & 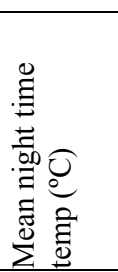 & 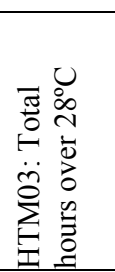 & 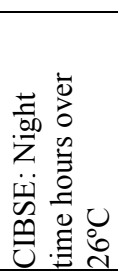 & 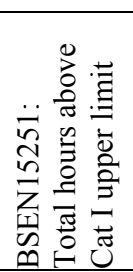 & 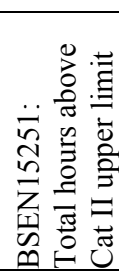 \\
\hline 2W27-SB1 & 27.8 & 22.9 & 23.4 & 0 & 18 & 105 & 12 \\
\hline 2W27-SB2 & 27.7 & 22.9 & 23.4 & 0 & 14 & 98 & 10 \\
\hline 2W27-6MB1 & 28.8 & 22.9 & 23.5 & 10 & 29 & 206 & 59 \\
\hline $2 \mathrm{~W} 27-6 \mathrm{MB} 2$ & 28.7 & 22.8 & 23.4 & 5 & 19 & 199 & 61 \\
\hline 2W27-NS & 29.0 & 24.4 & 25.0 & 19 & NA & NA & NA \\
\hline $2 \mathrm{~W} 27-\mathrm{CD}$ & 27.8 & 22.8 & 23.3 & 0 & NA & NA & NA \\
\hline
\end{tabular}

Notes (Appendix B):

1. The HTM03 threshold is based on dry bulb temperature and rest are based on dry resultant temperature.

2. CIBSE night time condition is not applicable to nurse station and corridors since there is no provision for sleeping

3. BSEN15251 conditions are applicable only to spaces with operable windows. 